\title{
The ecology of methane in streams and rivers: patterns, controls, and global significance
}

\author{
Emily H. Stanley, $, 1,4$ Nora J. Casson, ${ }^{1,3}$ Samuel T. Christel, ${ }^{1}$ John T. Crawford, ${ }^{2}$ Luke C. Loken,,${ }^{1}$ and \\ Samantha K. Oliver ${ }^{1}$ \\ ${ }^{1}$ Center for Limnology, University of Wisconsin, 680 North Park Street, Madison, Wisconsin 53706 USA \\ ${ }^{2}$ U.S. Geological Survey, 3215 Marine Street Suite E127, Boulder, Colorado 80303 USA
}

\begin{abstract}
Streams and rivers can substantially modify organic carbon (OC) inputs from terrestrial landscapes, and much of this processing is the result of microbial respiration. While carbon dioxide $\left(\mathrm{CO}_{2}\right)$ is the major end-product of ecosystem respiration, methane $\left(\mathrm{CH}_{4}\right)$ is also present in many fluvial environments even though methanogenesis typically requires anoxic conditions that may be scarce in these systems. Given recent recognition of the pervasiveness of this greenhouse gas in streams and rivers, we synthesized existing research and data to identify patterns and drivers of $\mathrm{CH}_{4}$, knowledge gaps, and research opportunities. This included examining the history of lotic $\mathrm{CH}_{4}$ research, creating a database of concentrations and fluxes (MethDB) to generate a global-scale estimate of fluvial $\mathrm{CH}_{4}$ efflux, and developing a conceptual framework and using this framework to consider how human activities may modify fluvial $\mathrm{CH}_{4}$ dynamics. Current understanding of $\mathrm{CH}_{4}$ in streams and rivers has been strongly influenced by goals of understanding OC processing and quantifying the contribution of $\mathrm{CH}_{4}$ to ecosystem $\mathrm{C}$ fluxes. Less effort has been directed towards investigating processes that dictate in situ $\mathrm{CH}_{4}$ production and loss. $\mathrm{CH}_{4}$ makes a meager contribution to watershed or landscape $\mathrm{C}$ budgets, but streams and rivers are often significant $\mathrm{CH}_{4}$ sources to the atmosphere across these same spatial extents. Most fluvial systems are supersaturated with $\mathrm{CH}_{4}$ and we estimate an annual global emission of $26.8 \mathrm{Tg} \mathrm{CH}_{4}$, equivalent to $\sim 15-40 \%$ of wetland and lake effluxes, respectively. Less clear is the role of $\mathrm{CH}_{4}$ oxidation, methanogenesis, and total anaerobic respiration to whole ecosystem production and respiration. Controls on $\mathrm{CH}_{4}$ generation and persistence can be viewed in terms of proximate controls that influence methanogenesis (organic matter, temperature, alternative electron acceptors, nutrients) and distal geomorphic and hydrologic drivers. Multiple controls combined with its extreme redox status and low solubility result in high spatial and temporal variance of $\mathrm{CH}_{4}$ in fluvial environments, which presents a substantial challenge for understanding its larger-scale dynamics. Further understanding of $\mathrm{CH}_{4}$ production and consumption, anaerobic metabolism, and ecosystem energetics in streams and rivers can be achieved through more directed studies and comparison with knowledge from terrestrial, wetland, and aquatic disciplines.
\end{abstract}

Key words: anaerobic respiration; carbon; database; ecosystem metabolism; efflux; global; greenhouse gas; heterogeneity; lotic; methanogenesis; methanotrophy.

\section{INTRODUCTION}

Growing awareness of ongoing and rapid changes in Earth's carbon cycle is motivating a new era of research aimed at improving our understanding of ecosystems as both responders to, and drivers of larger-scale

Manuscript received 6 June 2015; revised 16 October 2015; accepted 6 November 2015. Corresponding Editor: S. Findlay.

${ }^{3}$ Present address: Department of Geography, University of Winnipeg, 515 Portage Avenue, Winnipeg, Manitoba R3B 2E9, Canada

${ }^{4}$ E-mail: ehstanley@wisc.edu biogeochemical dynamics. In the case of streams and rivers, this has often taken the form of elucidating their role as processors of organic carbon (OC), a capacity that far exceeds their meager size and significantly influences the export of continental OC to marine environments (Cole et al. 2007, Battin et al. 2009, Aufdenkampe et al. 2011). Amplified OC processing has been inferred from observations of smaller export loads relative to inputs, rates of ecosystem respiration that exceed gross primary production, and/or occurrence of supersaturated concentrations of the products of OC decomposition, namely, carbon dioxide $\left(\mathrm{CO}_{2}\right)$ and methane $\left(\mathrm{CH}_{4}\right)$. 
Historically, conventional wisdom among aquatic scientists has been that $\mathrm{CH}_{4}$ should be scarce in streams and rivers because these ecosystems are usually well aerated and thus lack conditions required for $\mathrm{CH}_{4}$ generation and persistence (Zaiss et al. 1982, Dahm et al. 1991, Trimmer et al. 2012). Yet numerous studies have found significant amounts of $\mathrm{CH}_{4}$ in streams and rivers, often at concentrations far in excess of saturation. The recognition of inland waters, including fluvial systems, as $\mathrm{CH}_{4}$ sources occur within the larger context of a nearly threefold increase $(150 \%)$ in atmospheric concentrations since the 1750s, compared to a parallel increase in $\mathrm{CO}_{2}$ of $40 \%$ over the same period (IPCC 2013). While atmospheric $\mathrm{CH}_{4}$ enrichment is largely driven by human activities, natural sources are responsible for approximately one-third of all emissions (Nisbet et al. 2014). This contribution is predicted to increase due to positive feedbacks between climate change and ecosystem $\mathrm{C}$ cycling, including warmer temperatures fueling higher rates of organic matter breakdown and $\mathrm{CO}_{2}$ and $\mathrm{CH}_{4}$ release to the atmosphere (Yvon-Durocher et al. 2011, Bridgham et al. 2013, Hodgkins et al. 2014). At the same time, there are critical uncertainties regarding global sources and sinks of atmospheric $\mathrm{CH}_{4}$ (Kirschke et al. 2013). As a case in point, wetlands are the largest natural source of $\mathrm{CH}_{4}$ to the atmosphere, but lakes, reservoirs, and rivers also make substantial contributions that are not included in most global greenhouse gas (GHG) inventories (Bastviken et al. 2011). And beyond issues of climate change and accounting for sources of GHGs, examination of $\mathrm{CH}_{4}$ dynamics provides an opportunity to broaden our current understanding of ecological functioning of fluvial systems. $\mathrm{CH}_{4}$ is the energetic end member for ecosystem respiration, so its behavior over space and time should provide a unique perspective on metabolism and $\mathrm{C}$ cycling in streams and rivers.

Given the growing interest in streams and rivers as processors of $\mathrm{OC}$, the increased documentation of $\mathrm{CH}_{4}$ in these systems, the absence of any synthetic consideration of its spatial and temporal dynamics, and the opportunity to gain insights into ecosystem processes, we sought to review the current state of understanding of $\mathrm{CH}_{4}$ dynamics in fluvial ecosystems. While the focus is squarely on running waters, we also draw on research from lakes and wetlands to inform this synthesis. Our emphasis is on ecosystem-level patterns and controls of biogenic $\mathrm{CH}_{4}$, as coverage of the specific biochemical pathways, microbial taxa responsible for $\mathrm{CH}_{4}$ production and oxidation, and thermogenic sources have been addressed in several other excellent reviews (e.g., Etiope and Klusman 2002, Megonigal et al. 2004, Conrad 2009, Borrel et al. 2011, Bridgham et al. 2013, Chowdhury and Dick 2013). We pursue our goal by (1) examining the history of $\mathrm{CH}_{4}$ research in streams and rivers, (2) investigating patterns in concentrations and fluxes by creating and analyzing a database of published $\mathrm{CH}_{4}$ values, as well as using this database to better constrain the estimate of the global fluvial contribution to atmospheric $\mathrm{CH}_{4}$ inputs, (3) considering sources and controls of $\mathrm{CH}_{4}$ in streams and rivers, (4) suggesting how some widespread human activities may alter dynamics of $\mathrm{CH}_{4}$ in these ecosystems, and (5) highlighting major knowledge gaps and research opportunities.

Before diving into the analysis, it is useful to briefly review the major pathways and processes that affect $\mathrm{CH}_{4}$ concentrations and fluxes in streams and rivers. As in any ecosystem, $\mathrm{CH}_{4}$ in fluvial environments reflects a dynamic balance between production and consumption, import and export (Fig. 1). Delivery of $\mathrm{CH}_{4}$ to any one point in the channel can occur via diffusion from the atmosphere (influx), or by hydrological vectors of upstream flow or groundwater discharge. Conversely, flows leaving a site (downstream advection and groundwater recharge) have the capacity to export $\mathrm{CH}_{4}$, although the largest and most ecologically significant pathway of loss is gaseous efflux to the atmosphere. This latter flux can occur via diffusion, ebullition (escape of $\mathrm{CH}_{4}$ in gas bubbles that erupt out of sediments), or passage through vascular plants. Within the ecosystem itself, $\mathrm{CH}_{4}$ is generated from either the oxidation of $\mathrm{H}_{2}$ using $\mathrm{CO}_{2}$ as a terminal electron acceptor (TEA; hydrogenotrophic methanogenesis), or by the breakdown of acetate $\left(\mathrm{C}_{2} \mathrm{H}_{3} \mathrm{O}_{2}^{-}\right)$or a handful of other simple substrates (acetoclastic methanogenesis; Bridgham et al. 2013). Regardless of the pathway, methanogenesis represents the end of the line for respiration. That is, the free energy yield that results from $\mathrm{CH}_{4}$ generation is lower than from all other respiratory pathways. These energetic realities lead to the expectation that microbes relying on $\mathrm{O}_{2}, \mathrm{NO}_{3}^{-}, \mathrm{Mn}^{4+}, \mathrm{Fe}^{3+}, \mathrm{SO}_{4}^{2-}$, or other TEAs will outcompete methanogens, and thus suppress $\mathrm{CH}_{4}$ production. Conversely, oxidation of $\mathrm{CH}_{4}$ releases more energy than oxidation of similarly reduced TEAs such as sulfide, which means that $\mathrm{CH}_{4}$ is susceptible to rapid loss via this process, even under anaerobic conditions (see Hedin et al. 1998, Megonigal et al. 2004, Kietäväinen and Purkamo 2015 for further discussion). Indeed, methanotrophic (methane-oxidizing) microbes capitalize on this energetic opportunity, typically using $\mathrm{CH}_{4}$ as their sole source for both $\mathrm{C}$ and energy (Borrel et al. 2011), and growth of these methane-oxidizing autotrophs can create a link between $\mathrm{CH}_{4}$ and higher trophic levels in aquatic environments (Jones and Grey 2011).

Some major themes emerge from our investigation. First, review of the literature and the data extracted from these publications highlight a challenging dichotomy of fluvial systems being a globally significant $\mathrm{CH}_{4}$ source, yet characterized by fine-grained spatial and temporal variance. Second, and perhaps because of the large-scale significance of this flux, studies of $\mathrm{CH}_{4}$ dynamics are dominated by studies that adopt an "ecology of" rather than an "ecology in" approach (sensu Fisher 1997; Fig. 1). That is, the emphasis has been on quantifying net results of whole-ecosystem processes (efflux to the atmosphere or downstream transport of $\mathrm{CH}_{4}$ ), often using a black-box approach that focuses on inputs and outputs. The alternative "ecology in" perspective considers general ecological processes or phenomena using 


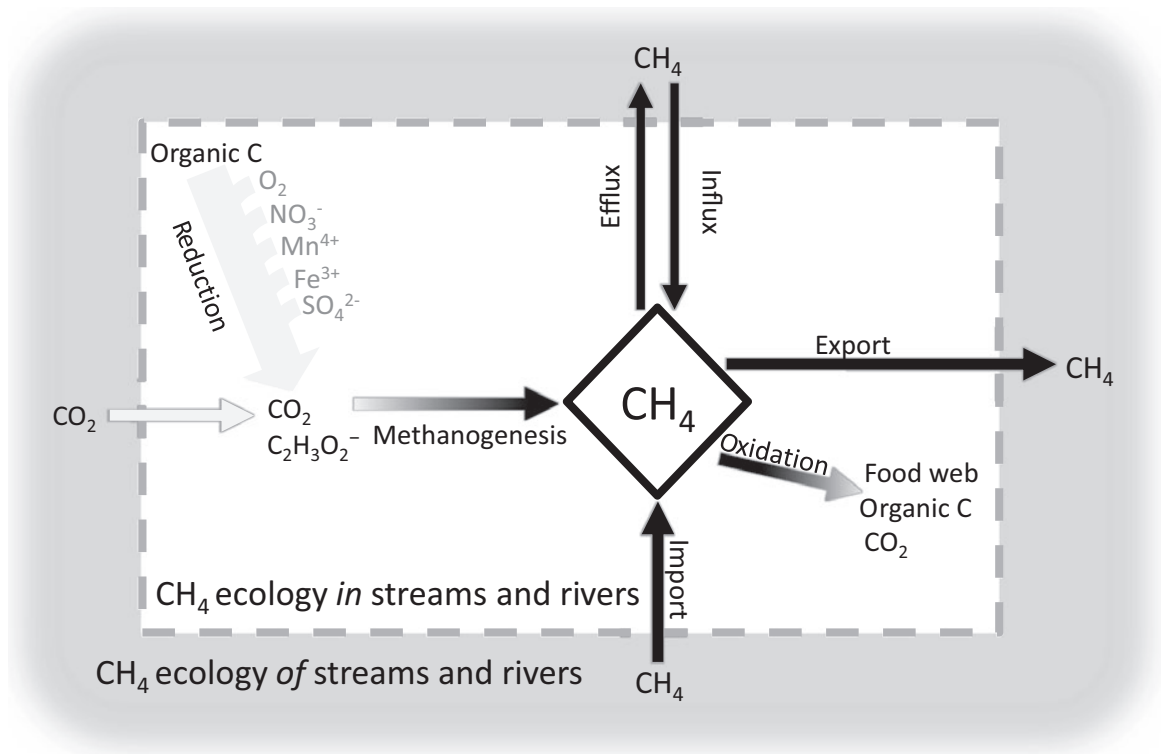

FIG. 1. Sources and fates of $\mathrm{CH}_{4}$ emphasizing the ecology of $\mathrm{CH}_{4}$ in streams and rivers and of streams and rivers. $\mathrm{CH}_{4}$ ecology in streams (white box) focuses on water column, benthic, and hyporheic processes of methanogenesis, methane oxidation (methanotrophy), and incorporation into stream food webs, the controls on these processes, and their influence on sediment and water column concentrations. Methanogenesis can occur via reduction of $\mathrm{CO}_{2}$ or decomposition of acetate $\left(\mathrm{C}_{2} \mathrm{H}_{3} \mathrm{O}_{2}^{-}\right)$or other select small organic molecules. These processes should only occur after more energetically favorable pathways of respiration can no longer proceed because alternative terminal electron acceptors (predominantly $\mathrm{O}_{2}, \mathrm{NO}_{3}^{-}, \mathrm{Mn}^{4+}, \mathrm{Fe}^{3+}, \mathrm{SO}_{4}^{2-}$, in descending order of energy yield associated with their reduction) have been exhausted. Alternatively, $\mathrm{CH}_{4}$ ecology of streams (gray shaded area) adopts the traditional "black box" approach of ecosystem ecology and emphasizes the net $\mathrm{CH}_{4}^{4}$ balance of lotic ecosystems, and thus focuses on import and export of $\mathrm{CH}_{4}$ via different hydrologic flow paths (surface discharge, hyporheic exchange, groundwater discharge) and gas movement into (influx) or out of (efflux, which can occur via diffusion, ebullition, or plant-mediated transport;) the stream or river. Gray shading of arrows denote pathways that do not directly involve $\mathrm{CH}_{4}$.

streams and rivers as arenas for research, and questions under investigation are relevant across different types of ecosystems (e.g., What controls methanogenesis? What favors $\mathrm{CH}_{4}$ incorporation into food webs?). Collectively, our ambition is to draw attention to this overlooked facet of metabolism in streams and rivers, the role of these ecosystems as sensitive and shifting contributors to regional GHG dynamics, and ultimately, to inspire further examination of the ecological dynamics of $\mathrm{CH}_{4}$ both in and of lotic ecosystems.

\section{The Trajectory of Methane Research in Streams AND RIVERS}

The history of the study of $\mathrm{CH}_{4}$ in streams and rivers is one of false starts and missed opportunities, and as a result, our understanding of $\mathrm{CH}_{4}$ dynamics in these systems currently lags behind that of lakes and wetlands. The earliest studies came from two unrelated directions, neither of which garnered particular attention. The first inspiration followed from widespread degradation of rivers in human-dominated landscapes. Inputs of raw sewage, industrial effluents, and fine sediments into European waterways led to water-quality degradation and $\mathrm{CH}_{4}$ production (Moens 1957, Zaiss and Kaltwasser 1979). These earliest studies not only highlighted
$\mathrm{CH}_{4}$ presence and production within channels, but also sought to identify major environmental controls, quantify the contribution of this pathway to total organic matter breakdown (Berger and Heyer 1989), and determine the significance of $\mathrm{CH}_{4}$ oxidation (Zaiss et al. 1982) and ebullition (Moens 1957) to the overall $\mathrm{CH}_{4}$ balance. The second inspiration for early fluvial $\mathrm{CH}_{4}$ studies came from oceanographers seeking to identify trace gas sources in estuarine and marine pelagic environments. Rivers were predicted to be unexpectedly important sources of $\mathrm{CH}_{4}$, and this prediction was validated by subsequent coastal and inland surveys (Swinnerton et al. 1969, Lamontagne et al. 1973, Wilkniss et al. 1978, de Angelis and Lilley 1987). However, these initial efforts from both directions failed to attract much attention and thus represented something of a research dead-end that was followed by a quiescent period that persisted for well over a decade.

During the 1990s and early 2000s, investigations into what was at the time an obscure topic for stream ecologists fell into two general categories. First, growing interest in hyporheic and riparian zone processes inspired a handful of studies on anaerobic metabolism and controls on redox-dependent biogeochemical transformations in these subsurface habitats (Jones et al. 1995, Hedin et al. 1998, Morrice et al. 2000). Works by Jones et al. (1995) 
and Jones and Mulholland (1998a, b) have been particularly influential in demonstrating hydrologic and geomorphological controls on $\mathrm{CH}_{4}$ production and delivery. The second motivation was, perhaps, accidental, but ultimately has proven to be a more enduring research avenue. Growing concern about climate change was finally drawing the attention of stream and river ecologists as they began to study $\mathrm{C}$ exports and the potential role of streams as $\mathrm{CO}_{2}$ sources. Among the flush of papers on fluvial $\mathrm{CO}_{2}$ pattern and process that emerged during this time (e.g., Neal et al. 1998, Finlay 2003, Jones et al. 2003), a few reported $\mathrm{CH}_{4}$ data as well (e.g., Kling et al. 1992, Hope et al. 2001, Dawson et al. 2002, 2004). There is a sense though, that the inclusion of $\mathrm{CH}_{4}$ was an afterthought, perhaps added in because it can be measured simultaneously with $\mathrm{CO}_{2}$ on many gas chromatographs. Indeed, the significance of $\mathrm{CH}_{4}$ as an agent of anthropogenic climate change was just beginning to come in to focus at the time (Hansen et al. 2000, Ramaswamy 2001), so its limited attention in streams and rivers is not necessarily surprising.

Following these relatively quiet forays, two publications triggered a sudden increase in research activity during the past five years. A watershed moment for aquatic $\mathrm{C}$ studies, and for $\mathrm{C}$ gases in particular, was the appearance of the landmark paper by Cole et al. (2007), which brought to light the outsized role of freshwaters in aggregate on global $\mathrm{C}$ processing. Subsequent work inspired by this recognition that "streams and rivers are not pipes" has been dominated by the goal of constructing more complete budgets to provide robust accountings of processing and loss. However, because $\mathrm{CH}_{4}$ typically represents a small fraction of total $\mathrm{C}$ pools and fluxes, it continued to be relegated to an ancillary status. $\mathrm{CH}_{4}$ finally acquired a leading role following the estimate by Bastviken et al. (2011) that the collective global $\mathrm{CH}_{4}$ efflux from lakes, reservoirs, and rivers was roughly the same magnitude in terms of its greenhouse warming potential as the terrestrial C sink. The 22-25fold greater warming potential of this gas (Forster et al. 2007) relative to the more common terminal product of OC breakdown $\left(\mathrm{CO}_{2}\right)$ provided fresh justification for examining $\mathrm{CH}_{4}$ in running waters. Ironically, while this keystone paper argued for the significance of $\mathrm{CH}_{4}$ emissions from all three types of aquatic systems, it relied on vanishingly few measurements from streams and rivers to help build the case. Nonetheless, the influence of these two papers on subsequent stream and river studies that include $\mathrm{CH}_{4}$ has been remarkable, and the renewed interest and increased data generation should facilitate better integration of aquatic systems into current understanding of the global $\mathrm{CH}_{4}$ balance.

\section{Patterns of Methane Concentration and Flux}

Our second objective was to collate and analyze available data on $\mathrm{CH}_{4}$ concentrations and fluxes in order to identify basic patterns and provide a global context for considering $\mathrm{CH}_{4}$ dynamics in streams and rivers. This involved developing and analyzing a database of published values (named MethDB) and comparing concentrations and fluxes among broad geographic categories or across physical and chemical gradients. The data and methods used to construct and analyze the database are reported in Stanley et al. (2015) and Appendix S1.

We identified 111 publications and three unpublished data sets that provided 1496 concentration and 523 flux measurements from 952 and 397 sites, respectively (Table 1; Stanley et al. 2015). Not surprisingly, the geographic distribution of studies is clustered, with heavy representation from Europe and conspicuous scarcities for vast continental areas of Asia/Eastern Europe, the Middle East, Canada, southern South America, and Australia (Fig. 2). Concentrations and diffusive fluxes spanned over six orders of magnitude, ranging from 0 to $386 \mu \mathrm{mol} / \mathrm{L}$ and -10.4 to $432 \mathrm{mmol} \cdot \mathrm{m}^{-2} \cdot \mathrm{d}^{-1}$, respectively (Table 1). Nearly all concentrations were supersaturated with respect to the atmospheric equilibrium, with only 16 sites reporting negative mean fluxes (i.e., net movement of $\mathrm{CH}_{4}$ from the atmosphere into water; Fig. 3), and the overall median concentration was two orders of magnitude greater than equilibrium. However, the assembled data set is likely to incorporate some degree of positive bias. If $\mathrm{CH}_{4}$ was not detected at a particular site, such a result may have been omitted rather than reported as zero (or below detection), as is suggested by the truncated distribution of mean concentrations. As a counter to this concern, spatially extensive surveys across large watersheds or regions found supersaturated concentrations in most or all sites (Campeau et al. 2014, Sawakuchi et al. 2014, Selvam et al. 2014, Borges et al. 2015) even when sites were randomly selected (Crawford et al. 2014a, Wallin et al. 2014). Thus, even with this possible bias, the picture that emerges from the growing body of literature is that $\mathrm{CH}_{4}$ supersaturation is the norm and most streams are $\mathrm{CH}_{4}$ sources to the atmosphere.

TABLE 1. Summary of published values of fluvial $\mathrm{CH}_{4}$ concentrations and fluxes.

\begin{tabular}{llll}
\hline \hline $\begin{array}{l}\text { Fluvial } \mathrm{CH}_{4} \\
\text { concentrations } \\
\text { and fluxes }\end{array}$ & Mean $\pm \mathrm{SD}(n)$ & Median & Range $(n)$ \\
\hline $\begin{array}{c}\text { Concentration } \\
(\mu \mathrm{mol} / \mathrm{L})\end{array}$ & $1.35 \pm 5.16(939)$ & 0.25 & 0 to $386(952)$ \\
$\begin{array}{c}\text { Diffusive flux } \\
\left(\mathrm{mmol} \cdot \mathrm{m}^{-2} \cdot \mathrm{d}^{-1}\right)\end{array}$ & $8.22 \pm 25.50(385)$ & 0.86 & $\begin{array}{c}-10.43 \text { to } \\
432.5(394)\end{array}$ \\
$\begin{array}{c}\text { Ebullitive flux } \\
\left(\mathrm{mmol} \cdot \mathrm{m}^{-2} \cdot \mathrm{d}^{-1}\right)\end{array}$ & $1.96 \pm 2.71(26)$ & 0.75 & 0 to $35.66(26)$ \\
$\begin{array}{c}\text { Total flux } \\
\left(\mathrm{mmol} \cdot \mathrm{m}^{-2} \cdot \mathrm{d}^{-1}\right)\end{array}$ & $4.23 \pm 8.41(26)$ & 1.23 & $<0.001$ to \\
$40.49(26)$
\end{tabular}

Notes: Means and medians are the overall grand means or medians of all site-aggregated means. Sample sizes differ for means and ranges because some papers only reported ranges. Total flux refers to values that either summed separate measurements of ebullition and diffusion or reported a combined value without distinguishing between the two pathways. 


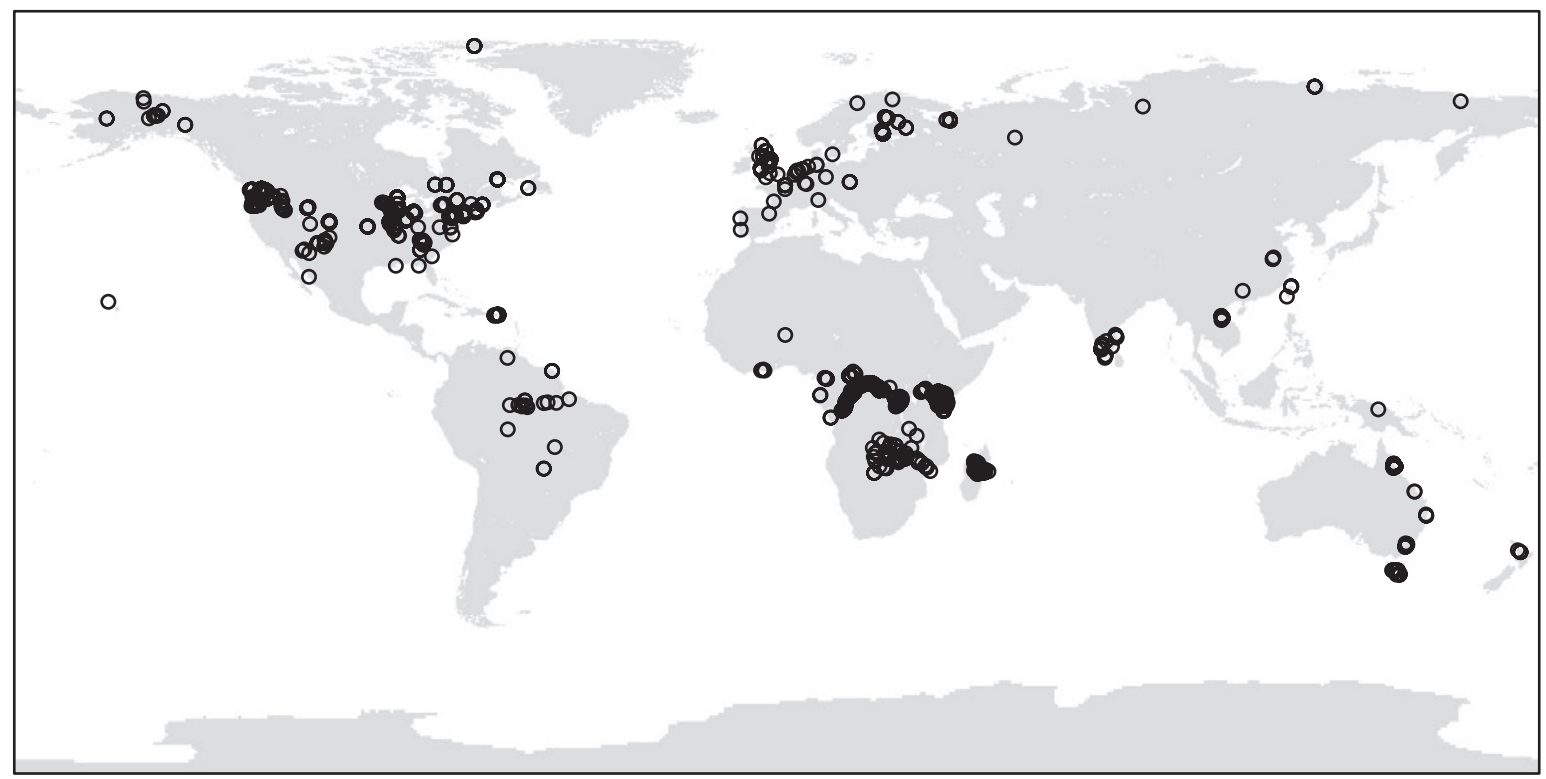

FIG. 2. Locations of sites reporting methane concentration and/or flux data for streams and rivers incorporated into MethDB.
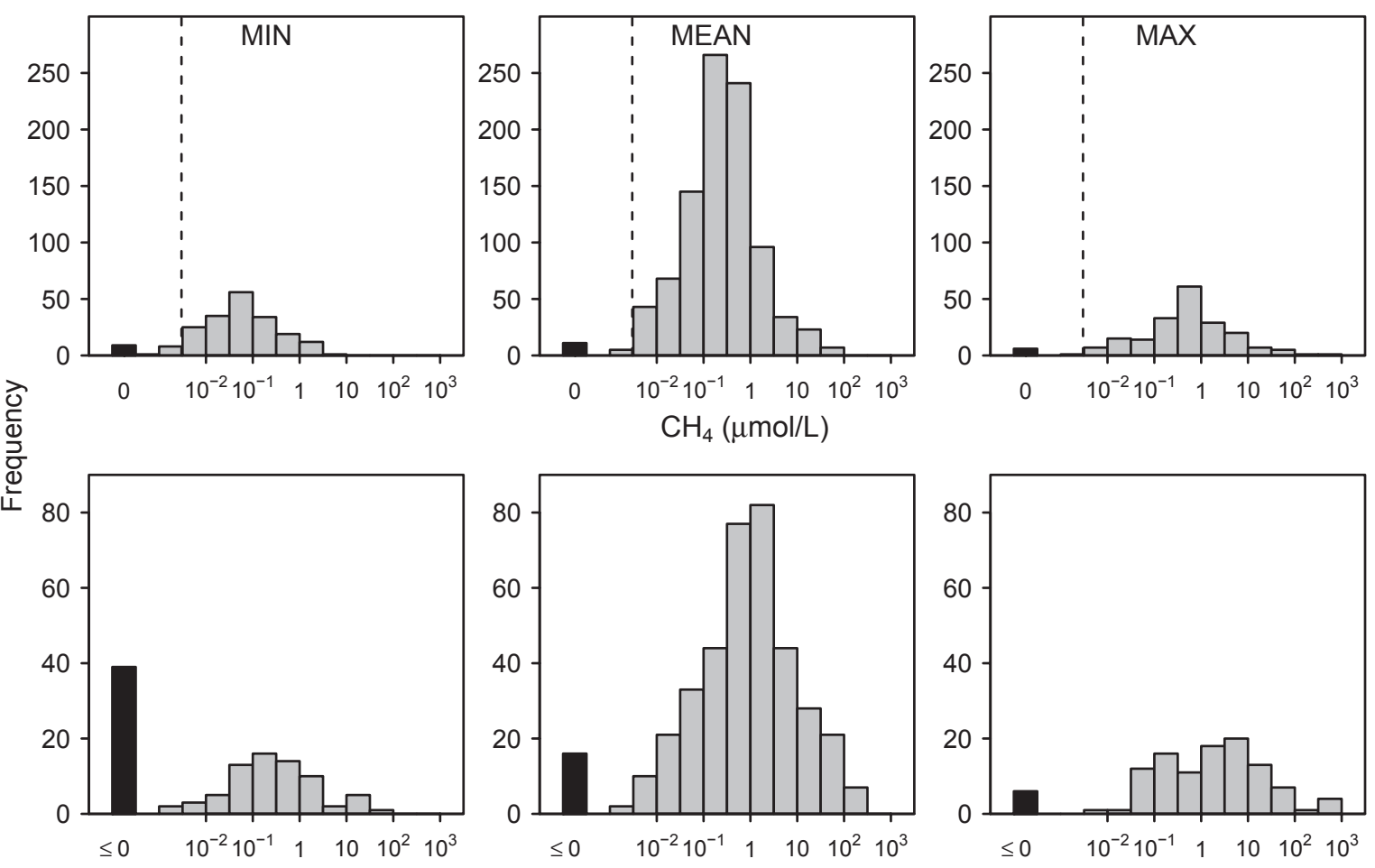

$\mathrm{CH}_{4}$ diffusive flux $\left(\mathrm{mmol} \cdot \mathrm{m}^{-2} \cdot \mathrm{d}^{-1}\right)$

FIG. 3. Frequency distributions of site-specific minima, means, and maxima $\mathrm{CH}_{4}$ concentrations (top; $n=200,939,200$ sites) and diffusive fluxes (bottom; $n=110,385,110$ ). The vertical dashed line represents the atmospheric equilibrium concentration (top row) calculated at sea level (elevation $=0 \mathrm{~m}$ ) using an atmospheric concentration of $0.193 \mathrm{~Pa}$ and mean reported stream temperature from the database $\left(16.2^{\circ} \mathrm{C}\right)$. Black bars represent sites with concentrations reported as zero or below the detection limit (top row) or with negative efflux values (bottom row). 
Exploration of coarse-scale patterns revealed some differences among broad geographic categories. No differences were detected among sites as a function of size, while a variety of differences existed among biomes and land use/land cover groups (Figs. 4 and 5; Table 2). Median concentrations were high in boreal forests, xeric regions, temperate grasslands, and tropical broadleaf forests, and low at temperate coniferous forest sites. Fluxes were greatest in temperate broadleaf forests, all tropical biomes, and the tundra, while fluxes were low in temperate grasslands despite high median concentrations in this biome type (Figs. 4 and 5). High fluxes in divergent biomes such as tundra and tropical regions are consistent with an absence of a relationship between $\mathrm{CH}_{4}$ and latitude (Fig. 6).

The clearest signal that emerged from the large-scale analyses was a positive effect of wetlands and human activity on $\mathrm{CH}_{4}$. Sites in land use and anthrome (sensu Ellis et al. 2010) groups representing wetlands, agriculture, and/or urban areas were characterized by higher median concentrations and diffusive fluxes (Figs. 4 and 5). Similarly, the positive relationship between dissolved organic carbon (DOC) and, to a lesser degree, ammonium $\left(\mathrm{NH}_{4}^{+}\right)$and $\mathrm{CH}_{4}$ concentrations (Fig. 6, Appendix S1) were the strongest among all driver variables considered, consistent with high concentrations of these constituents in urban sites, although the DOC- $\mathrm{CH}_{4}$ relationship is also likely to be the product of often-high values for wetland-dominated sites. In the case of the urban influence, there are several examples across multiple continents of elevated $\mathrm{CH}_{4}$ in association with $\mathrm{OM}$ - and $\mathrm{NH}_{4}{ }^{+}$-rich effluent discharges (e.g., Europe [Zaiss et al. 1982, Garnier et al. 2013], Asia [Yang et al. 2015], Africa [Adams and Simiyu 2009, Marwick et al. 2014]). Rajkumar et al. (2008) provide a particularly vivid example in their description of the highly polluted Adyar River, India as "fizzing" because of vigorous production and ebullition of nitrous oxide $\left(\mathrm{N}_{2} \mathrm{O}\right)$ and $\mathrm{CH}_{4}$ associated with large inputs of untreated human waste.

Despite detection of significant differences among land uses and biomes, substantial variability is apparent within and among categories and across temperature, latitude,


FIG. 4. Box plots of $\mathrm{CH}_{4}$ concentrations by system size, biome (top row), land use category, and anthrome (bottom row). Biome assignments were derived from Olson et al. (2001) and anthromes from Ellis et al. (2010). Significant differences $(P<0.05)$ among categories are indicated by letters above boxes, and sample sizes are in parentheses below category names. See Table 2 for Kruskal-Wallis summary statistics and Appendix S1 for further details regarding category assignment and statistical analyses. Biome abbreviations are BFT, boreal forests/taiga; DXS, deserts and xeric shrublands; TEB, temperate broadleaf and mixed forests; TEC, temperate coniferous forests; TEG, temperate grasslands, savannas, and shrublands; TRD, tropical and subtropical dry broadleaf forests; TRG, tropical and subtropical grasslands, savannas, and shrublands; TRM, tropical and subtropical moist broadleaf forest; TUN, tundra. Box mid lines represent medians; lower and upper box boundaries denote 25 th and 75 th percentiles, respectively; whiskers indicate approximate $95 \%$ confidence intervals and points are outliers. 

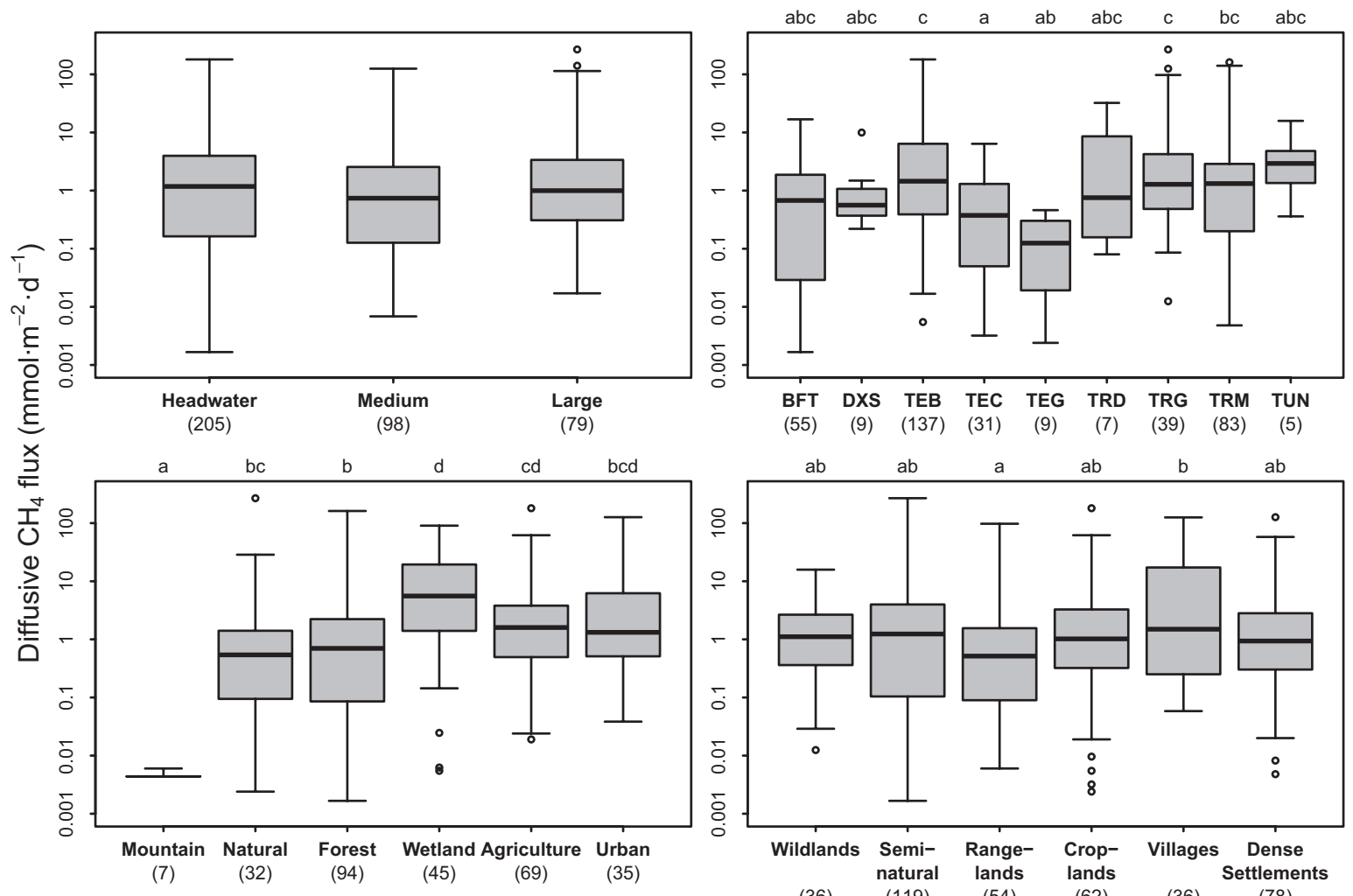

FIG. 5. Box plots of diffusive $\mathrm{CH}_{4}$ fluxes. See Fig. 4 for details.

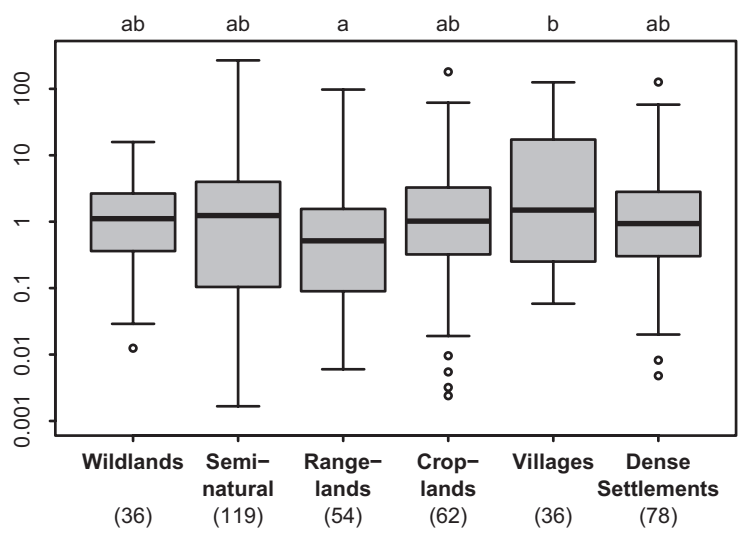

TABLE 2. Test statistics $\left(\chi^{2}\right)$ and degrees of freedom (df) for Kruskal-Wallis tests for differences among sites as a function of size, biome type, anthrome type, and land use (see Fig. 3).

\begin{tabular}{lrrrr}
\hline \hline & $\chi^{2}$ & df & $n$ & \multicolumn{1}{c}{$P$} \\
\hline Concentration & & & & \\
Size & 0.88 & 2 & 917 & 0.645 \\
Biome & 93.24 & 8 & 932 & $<0.001$ \\
Anthrome & 35.17 & 5 & 445 & $<0.001$ \\
Land use & 67.03 & 5 & 939 & $<0.001$ \\
Diffusive flux & & & & \\
Size & 2.19 & 2 & 382 & 0.334 \\
Biome & 35.69 & 8 & 375 & $<0.001$ \\
Anthrome & 42.49 & 5 & 282 & $<0.001$ \\
Land use & 13.06 & 5 & 385 & 0.023 \\
\hline
\end{tabular}

Notes: Sample sizes differ among tests due to differences in availability of data describing site characteristics. For significant Kruskal-Wallis tests, pairwise comparisons using Bonferronicorrected Wilcoxon paired $t$ tests were used to identify differences among groups and these results are reported in Figs. 5 and 6.

and chemical gradients. This high variance reflects both the practical issue of mixed and often limited sampling strategies and the reality that variance in $\mathrm{CH}_{4}$ at smaller spatial scales may overwhelm any larger-scale patterns. Such pronounced variance is a consistent finding among spatially or temporally detailed sampling regimes. For example, summer $\mathrm{CH}_{4}$ concentrations varied three orders of magnitude (2.43-2906 $\mathrm{Pa}$, or approximately 0.045-54.2 $\mu \mathrm{mol} / \mathrm{L}, n=129$ ) across two adjacent boreal river basins (Campeau et al. 2014) and $\mathrm{CH}_{4}$ concentrations varied by a factor of $50(0.05-2.4 \mu \mathrm{mol} / \mathrm{L}$ from over 175 sample dates) in a single UK peatland stream over a five-year study (Dinsmore et al. 2013). Given that within-stream or within-basin variability can approach the magnitude of the total variability seen across the entire globe, we need to entertain the very real possibility that clear, overarching global-scale drivers or predictors simply do not exist for this respiratory end member and that its distribution and efflux are subject to strong local control.

\section{Ecosystem Perspectives of Methane}

\section{Fluxes in context}

The recent burst of $\mathrm{CH}_{4}$-related articles inspired by Cole et al. (2007) and Bastviken et al. (2011) share common goals of quantifying emissions, comparing these rates to other atmospheric sources, and/or determining the contribution of $\mathrm{CH}_{4}$ to stream, watershed, or regional $\mathrm{C}$ budgets. These studies have largely sought to answer the question: does $\mathrm{CH}_{4}$ export from streams and rivers represent a major pathway of $\mathrm{C}$ loss, and how do emissions from lotic ecosystems compare to their surrounding watersheds or to other aquatic habitats? As a result, the focus has been less on controls of $\mathrm{CH}_{4}$ 

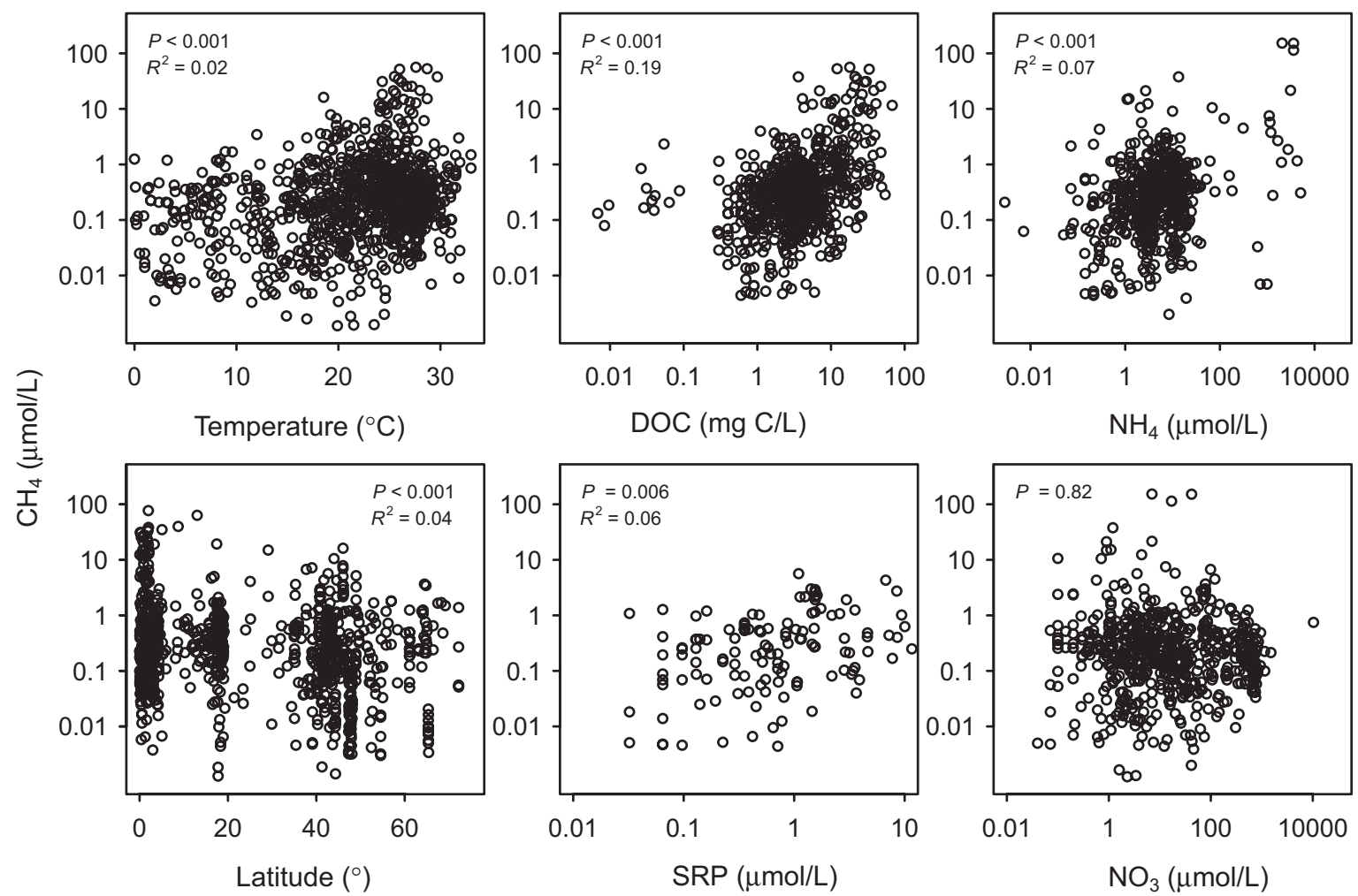

FIG. 6. $\mathrm{CH}_{4}$ concentration vs. water temperature, latitude, dissolved organic carbon (DOC), soluble reactive phosphorus (SRP), ammonium $\left(\mathrm{NH}_{4}^{+}\right)$, and nitrate $\left(\mathrm{NO}_{3}^{-}\right)$concentrations and associated $R^{2}$ and $P$ values (for significant models) for linear regressions. For latitude, southern hemisphere values were plotted as positive values, and average site $\mathrm{CH}_{4}$ concentration was plotted against latitude for sites with multiple measurements. For all other plots, all individual site-date combinations with appropriate chemistry data were included (i.e., a site sampled 12 times per year for nutrient and $\mathrm{CH}_{4}$ concentrations is represented by 12 data points).

production or consumption $\left(\mathrm{CH}_{4}\right.$ ecology in streams) and more on quantifying the contribution of its export from these fluvial systems ( $\mathrm{CH}_{4}$ ecology of streams). So what have these studies revealed about the significance of $\mathrm{CH}_{4}$ fluxes from streams and rivers?

$\mathrm{C}$ budget studies consistently demonstrate that fluvial $\mathrm{CH}_{4}$ contributions to watershed and regional $\mathrm{C}$ pools and fluxes are fleetingly small- often composing less than $1 \%$ of total exports (e.g., Naiman et al. 1987, Hope et al. 2001, Neu et al. 2011, Striegl et al. 2012). While this trivial contribution to whole-catchment and regional mass balances is consistent across diverse settings, it is also likely that most studies have underestimated stream and river fluxes because of limited sampling regimes and because the vast majority of studies do not account for ebullition (e.g., see Table 1) or in some cases, do not include gaseous fluxes at all (e.g., Flessa et al. 2008). When the focus is narrowed down to different sources of atmospheric $\mathrm{CH}_{4}$, fluvial emissions become more prominent. $\mathrm{CH}_{4}$ outgassing from streams and rivers can be similar to or exceed rates from lakes or other landscape features on a per unit area basis (Reeburgh et al. 1998, Juutinen et al. 2013, Lundin et al. 2013) and, in at least two cases, on a total area basis (i.e., accounting for the total surface area of each type of aquatic system within the catchment; Campeau et al. 2014, Selvam et al. 2014). But these results are not universal, as others report lower areal and total emission rates from streams and rivers compared to other aquatic (Saarnio et al. 2009) or watershed (Wilcock and Sorrell 2008, Garnier et al. 2013) sources.

At the global scale, the initial estimate by Bastviken et al. (2011) suggested that total efflux of $\mathrm{CH}_{4}$ from inland waters (excluding wetlands) is dominated by the contribution made by lakes. But as was mentioned earlier, the riverine flux was derived from a very limited number of measurements (13 values from six publications), leading the authors to warn that this particular result "called for caution." Given our larger, more representative, data set, we updated the global estimate for streams and rivers and compared it to available estimates from other aquatic ecosystems. The spatial and temporal variance of existing data coupled with erratic geographic coverage present obvious challenges for generating large-scale estimates with high certainty (Ortiz-Llorente and Alvarez-Cobelas 2012, Billett and Harvey 2013). As we noted earlier, simple or clear scaling rules are not currently available, and given the limited differences among biomes, land uses, system sizes, and latitude, as well as substantial variability 
within individual sites or catchments, we see no current advantage to segmenting estimates by any of these broad categories when generating an upscaled value for evasion. Hence, we calculated global river $\mathrm{CH}_{4}$ emissions using a simple bootstrapping approach based on the distribution of mean/median diffusive $\mathrm{CH}_{4}$ fluxes extracted from our database multiplied by global stream and river area from Raymond et al. (2013) (see Appendix S1 for further details). Ebullitive fluxes were excluded due to the scarcity and geographic bias of existing data, making our estimate conservative. This calculation yielded an estimate of $26.8 \mathrm{Tg} \mathrm{CH}_{4}$ per year (5th-95th percentiles: $0.01-160 \mathrm{Tg} / \mathrm{yr}$ ) emitted from streams and rivers globally (Table 3). This estimate is more than an order of magnitude greater than that of Bastviken et al. (2011) $\left(1.5 \mathrm{CH}_{4}\right.$ $\mathrm{Tg} / \mathrm{yr}$ ), which is not surprising given their limited number of flux values, all but one of which were below the mean $\mathrm{CH}_{4}$ flux from our larger database.

This result suggests that flowing waters may contribute as much or more $\mathrm{CH}_{4}$ to the atmosphere as other natural sources including wildfires, termites, $\mathrm{CH}_{4}$ hydrates, and permafrost combined ( $\left.\sim 21 \mathrm{Tg} \mathrm{CH}_{4} / \mathrm{yr}\right)$, and conversely is equivalent to the magnitude of $\mathrm{CH}_{4}$ uptake by terrestrial soils ( $28 \mathrm{Tg} \mathrm{CH}_{4} / \mathrm{yr}$; Kirschke et al. 2013). It is tricky to compare the riverine flux to other freshwater ecosystems because of the high uncertainty and diversity of estimates (Table 3), but it is on par with $\sim 15 \%$ and $40 \%$ of wetland and lake-specific emissions estimates, respectively, and $>50 \%$ of the current estimate for efflux for all freshwaters (lakes, reservoirs, and rivers) provided by Kirschke et al. (2013) (Table 3). Thus, despite the uncertainty, streams and rivers appear to be globally significant and underappreciated $\mathrm{CH}_{4}$ sources to the atmosphere and should no longer be excluded from global $\mathrm{CH}_{4}$ budgets.

\section{Methane and metabolism}

While the mass balance/budget framework considered above provides one perspective on the general significance of fluvial $\mathrm{CH}_{4}$, another approach is to consider its relevance to total ecosystem metabolism, that is, to determine the fraction of ecosystem respiration (ER) that can be attributed to methanogenesis or the contribution of methanotrophy to primary production. Unfortunately, making these determinations is operationally difficult and has rarely been done for streams. Consistent with the traditional view of these ecosystems as well-aerated environments, and given its ease of measurement, whole-system metabolism is overwhelmingly estimated by changes in dissolved oxygen over time. Clearly, this approach prohibits direct quantification of any anaerobic pathway, not just methanogenesis. $\mathrm{C}$ fixed in association with $\mathrm{CH}_{4}$ oxidation is also not resolvable from measures of daily changes in dissolved oxygen. We are aware of only two stream studies that have attempted to determine the contribution of methanogenesis to total ER, and they vary from $<6 \%$ (Jones et al. 1994) to $59-87 \%$ (Berger and Heyer 1989). Estimates of $\mathrm{CH}_{4}$ oxidation are similarly rare and wide-ranging. In keeping with the history of false starts, there were a handful of early attempts to quantify this process and its contribution to the overall ecosystem $\mathrm{CH}_{4}$ balance and efflux (Zaiss et al. 1982, de Angelis and Scranton 1993, Lilley et al. 1996), followed by a long hiatus in which this process was not specifically measured. Results are difficult to compare because of different methods or ways rates are expressed, but collectively they suggest both trivial and substantial roles for oxidation. For example, oxidation rates vary from $<4 \%$ of methanogenesis (Zaiss et al. 1982, Lilley et al. 1996, Bussmann 2013) to being able to deplete $35-70 \%$ of the $\mathrm{CH}_{4}$ pool per day (de Angelis and Scranton 1993) or exceeding measured rates of methanogenesis (Shelley et al. 2015). Quantifications of the contribution of methanotrophy to total autotrophy are also based on very few studies. Chemoautotrophic $\mathrm{C}$ fixation via both nitrification and $\mathrm{CH}_{4}$ oxidation accounted for $<1 \%$ of all $\mathrm{C}$ fixed in a highly productive desert stream (Jones et al. 1994). Similarly, across 15 southern England streams, methanotrophy averaged 4\% of photosynthetic $\mathrm{C}$ fixation during August. However, at some sites, the contribution reached $40 \%$ or more, and these authors suggested that at times $\mathrm{CH}_{4}$ oxidation may account for most, or perhaps even all, of the instantaneous C fixation (Shelley et al. 2014). But overall, it is simply not possible to draw any firm conclusion regarding patterns or general significance of these processes to whole ecosystem rates at this point because of the severe data limitation.

Given that it is currently intractable to quantify methanogenesis as a routine part of metabolism studies, a reasonable first step is to develop a better sense of the general significance of this process across a range of sites. One strategy for taking this step is to examine ratios of $\mathrm{CH}_{4}$ to $\mathrm{CO}_{2}$ for concentration, production, or flux (e.g., Jones and Mulholland 1998b, Wallin et al. 2014, Shelley et al. 2015). This ratio is incorporated into several process-based wetland models based on the logic that methanogenesis is some proportion of total ER, and that conditions that determine overall ER (i.e., $\mathrm{CO}_{2}$ production) also determine $\mathrm{CH}_{4}$ production ( $\mathrm{Zhu}$ et al. 2014). And while the proportion of $\mathrm{CH}_{4}$ to $\mathrm{CO}_{2}$ production in wetlands is variable, it is constrained to a known range, and thus can either be fixed or treated as a parameter that can be adjusted through model fitting (Wania et al. 2010). Given the distinctly different environmental conditions of streams and rivers, we cannot assume that the same scaling of methanogenesis with ER occurs. Instead, existence of such a relationship (and concomitantly, existence of a relatively constrained range of the $\mathrm{CH}_{4}: \mathrm{CO}_{2}$ ratio) can be treated as a hypothesis that we refer to as the "anaerobic scaling hypothesis" that is in need of further interrogation.

In support of the anaerobic scaling hypothesis for streams and rivers, a consistent relationship has been reported between denitrification and ER, either due to the consumption of $\mathrm{O}_{2}$ by aerobes to open the door for 
TABLE 3. Summary of global-scale estimates of $\mathrm{CH}_{4}$ emissions $\left(\mathrm{Tg} \mathrm{CH}_{4} / \mathrm{yr}\right)$ for inland waters, including wetlands.

\begin{tabular}{|c|c|c|c|c|c|}
\hline System type and reference & Efflux type & Mean & Median & Min & Max \\
\hline \multicolumn{6}{|l|}{ Rivers } \\
\hline Bastviken et al. (2011) & $\mathrm{D}$ & 1.5 & & & \\
\hline Sawakuchi et al. (2014) & $\mathrm{D}$, partial E & & & 1.8 & 2.3 \\
\hline Borges et al. $(2015) \dagger$ & $\mathrm{D}$ & & & 4.4 & 5.4 \\
\hline This study, stream area method & $\mathrm{D}$ & 26.8 & 2.85 & -34.4 & 1010 \\
\hline This study, ratio method & $\mathrm{D}$ & 28.0 & 11.8 & 0.03 & 261 \\
\hline \multicolumn{6}{|l|}{ Lakes } \\
\hline Walter et al. (2007) & $\mathrm{E}$ & 31.7 & & & \\
\hline Bastviken et al. (2011) & $\mathrm{D}+\mathrm{E}$ & 71.6 & & & \\
\hline \multicolumn{6}{|l|}{ Reservoirs } \\
\hline St. Louis et al. (2000) & $\mathrm{D}$, partial E & 70 & & & \\
\hline Lima et al. (2008), reservoir surfaces & $\mathrm{D}+\mathrm{E}$ & 3.5 & & & \\
\hline Lima et al. (2008), downstream from reservoirs & $\mathrm{D}+\mathrm{E}$ & 100 & & & \\
\hline Lima et al. (2008), total reservoir effect & $\mathrm{D}+\mathrm{E}$ & 104 & & & \\
\hline Bastviken et al. (2011) & $\mathrm{D}$, partial E & 20 & & & \\
\hline Barros et al. (2011), hydropower reservoirs & $\mathrm{D}+\mathrm{E}$ & 4.5 & & & \\
\hline Barros et al. (2011), all reservoirs & $\mathrm{D}+\mathrm{E}$ & 64 & & & \\
\hline Maeck et al. (2013) $\$$ & $\mathrm{D}+\mathrm{E}$ & 3.4 & & 0.9 & 7.2 \\
\hline Hertwich (2013), hydropower reservoirs & $\mathrm{D}+\mathrm{E}$ & 9.7 & & & \\
\hline \multicolumn{6}{|l|}{ Freshwaters§ } \\
\hline Bastviken et al. (2011) & $\mathrm{T}$ & 103.3 & & & \\
\hline Kirschke et al. (2013) & $\mathrm{T}$ & 40 & & 8 & 73 \\
\hline \multicolumn{6}{|l|}{ Wetlands } \\
\hline Bridgham et al. (2013), all & $\mathrm{T}$ & 166 & 164 & 80 & 280 \\
\hline Bridgham et al. (2013), top-down modeling & $\mathrm{T}$ & & 181 & 92 & 280 \\
\hline Bridgham et al. (2013), bottom-up scaling & $\mathrm{T}$ & & 107 & 80 & 111 \\
\hline Melton et al. (2013) & $\mathrm{T}$ & 190 & & 140 & 260 \\
\hline Kirschke et al. (2013), top-down modeling & $\mathrm{T}$ & 175 & & 142 & 208 \\
\hline Kirschke et al. (2013), bottom up scaling & $\mathrm{T}$ & 217 & & 177 & 284 \\
\hline
\end{tabular}

Notes: Efflux types identify the emission pathway(s) included in the estimate: diffusion (D), ebullition (E), or total (T), which represents the composite of diffusion, ebullition, and plant-mediated emissions. Partial E refers to estimates that incorporated ebullition data when available.

$\dagger$ Values estimated by combining the global estimate from Bastviken et al. (2011) with estimated emissions from tropical rivers of sub-Saharan Africa by Borges et al. (2015), for comparison to the approach taken by Sawakuchi et al. (2014).

tEstimate represents "hot-spot zones in rivers"; i.e., effluxes from small impoundments multiplied by river area was added on to total river flux value from Bastviken et al. (2011).

$\S$ Lakes, reservoirs, rivers.

anaerobic $\mathrm{R}$, or because streams with high ER likely have large pools of organic matter needed to fuel any type of respiration (Christensen et al. 1990, Mulholland et al. 2008). Additional support is provided by regional stream surveys that found relatively constrained $\mathrm{CH}_{4}: \mathrm{CO}_{2}$ relationships for concentration (Wallin et al. 2014, Campeau and del Giorgio 2014). In contrast, ratios of $\mathrm{CH}_{4}: \mathrm{CO}_{2}$ fluxes derived from MethDB varied widely, ranging across six orders of magnitude $\left(1.73 \times 10^{-5}\right.$ to $5.17 ; n=238$, with negative fluxes of both $\mathrm{CH}_{4}$ and $\mathrm{CO}_{2}$ excluded for ease of interpretation), far exceeding the range of ratios for wetlands (Segers 1998) (Fig. 7). At face value, this result does not seem to support the anaerobic scaling hypothesis. There is some suggestion that high $\mathrm{CH}_{4}: \mathrm{CO}_{2}$ ratios are frequently associated with greater human modification of streams. The highest ratios $(>0.1 ; n=32)$ were observed in highly modified systems, including drainage ditches cut in agricultural peatlands (Schrier-Uijl et al. 2011), downstream of large, tropical reservoirs (Guérin et al. 2006, 2007, Kemenes et al. 2007), sites receiving organic-rich industrial effluents (Adams and Simiyu 2009), and also rivers located within extensive floodplain systems (Borges et al. 2015). In contrast, the lowest ratios $(<0.0001$; $n=16$ ) were predominately from relatively undisturbed boreal or temperate forests (Beaulieu 2007, Silvennoinen et al. 2008).

Another approach for evaluating the anaerobic scaling hypothesis is to follow the lead of wetland models and use the $\mathrm{CH}_{4}: \mathrm{CO}_{2}$ ratio as an alternative means of generating a global-scale estimate of fluvial $\mathrm{CH}_{4}$ emission. If there is some general relationship between whole-ecosystem respiration and methanogenesis, then global emission estimated from $\mathrm{CO}_{2}$ efflux combined with the $\mathrm{CH}_{4}: \mathrm{CO}_{2}$ ratio should be comparable to our earlier 


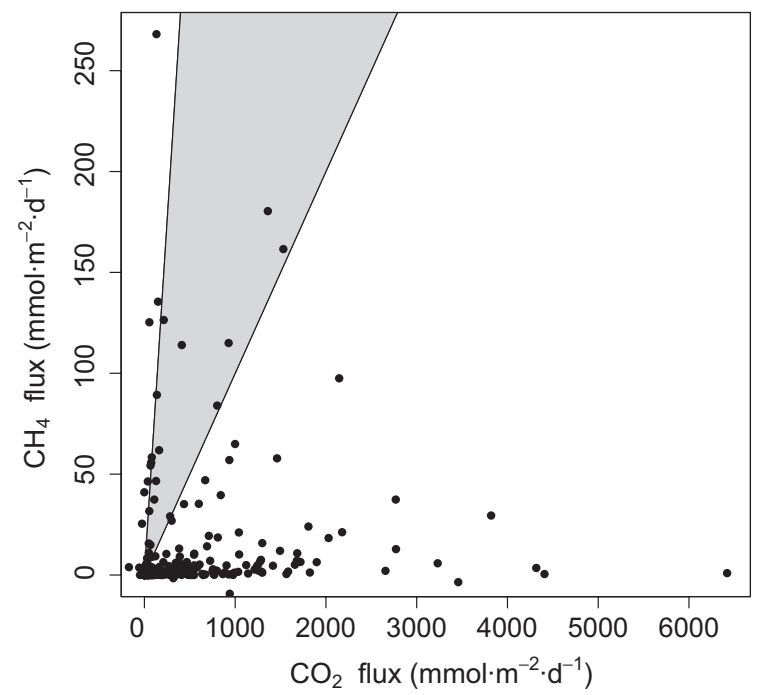

FIG. 7. Scatterplot of diffusive fluxes of $\mathrm{CH}_{4}$ vs. $\mathrm{CO}_{2}$ for all MethDB site-date combinations reporting both fluxes. The gray shaded area denotes the range of values for fluxes from wetlands based on data summarized by Segers (1998).

direct estimate based on $\mathrm{CH}_{4}$ alone. We again used a bootstrapping approach in which we created a distribution of global stream $\mathrm{CO}_{2}$ emissions based on the mean and 5th-95th percentiles from Raymond et al. (2013) (a reasonably well constrained estimate) multiplied by the distribution of the $\mathrm{CH}_{4}: \mathrm{CO}_{2}$ diffusive flux ratios from MethDB. This approach yielded an unrealistically high estimate of $243 \mathrm{Tg} \mathrm{CH}_{4} / \mathrm{yr}$ (5th-95th percentile range: 0.4-957 $\left.\mathrm{Tg} \mathrm{CH}_{4} / \mathrm{yr}\right)$. However, this mean value appears to be inflated by the small number of highly disturbed sites where the $\mathrm{CH}_{4}$ efflux is very high in both absolute terms and relative to the $\mathrm{CO}_{2}$ flux. With the 32 sites mentioned above excluded, the estimate of global $\mathrm{CH}_{4}$ efflux drops to $28.0 \mathrm{Tg} \mathrm{CH}_{4} / \mathrm{yr}$ (5th-95th percentile range: $0.3-130 \mathrm{Tg}$ $\mathrm{CH}_{4} / \mathrm{yr}$ ), a value that is surprisingly comparable to the estimate based on $\mathrm{CH}_{4}$ (26.8 Tg $\mathrm{CH}_{4} / \mathrm{yr}$; 5th-95th percentile range, 0.01-160; Table 3). While the uncertainty associated with both estimates is quite high, their similarity nonetheless provides some empirical support for the anaerobic scaling hypothesis at the global scale and additional confidence in our global efflux estimate. Overall, these preliminary tests are limited in their strength and provide an ambiguous picture about how tightly or at what spatial scale methanogenesis and total ER are linked in streams and rivers. Regardless of the veracity of the hypothesis, the utility of the ratio as a simple index of the balance or status of ecosystem respiration seems clear, and its application to MethDB suggests a series of questions applicable to both site-specific and global scales, such as: When or where do $\mathrm{CH}_{4}: \mathrm{CO}_{2}$ ratios deviate strongly from more wetland-like ratios? Are high relative $\mathrm{CH}_{4}$ efflux rates driven by high rates of $\mathrm{CH}_{4}$ production or inputs from external sources, low rates of $\mathrm{CH}_{4}$ oxidation, or low overall ER $\left(\mathrm{CO}_{2}\right.$ production)? How does the ratio shift across seasons or in response to floods? Are high ratios consistently characteristic of some types of disturbance but not others?

\section{A Framework for Controls on $\mathrm{CH}_{4}$ in Streams and RIVERS}

The lack of clear global-scale predictors and the high variance in concentrations and fluxes undoubtedly reflect multiple controls on the production and persistence of $\mathrm{CH}_{4}$ in streams and rivers. To sort through potential influences and guide the next section of the paper, we developed a quasi-hierarchical framework that includes two sets of drivers and their known or expected effects on methanogenesis and $\mathrm{CH}_{4}$ efflux (Fig. 8). Nutrients, organic matter $(\mathrm{OM})$, terminal electron acceptors (TEAs), and temperature can have indirect effects on $\mathrm{CH}_{4}$, but are defined here as proximate controls due to their direct involvement in biochemical processes of $\mathrm{CH}_{4}$ generation. Geomorphology and hydrology make up a second set of drivers that we refer to as "distal controls." The rationale underlying this framework is based on the simple contention that the presence of $\mathrm{CH}_{4}$ at any site and time is the result of the habitat or conditions suitable for its generation being present either in the channel or linked to the channel via water flow. The first level of the framework is composed of components that dictate this habitat suitability: appropriate thermal conditions (temperature), fuel for respiration (organic matter), redox status (TEAs), and nutrients needed to support growth of methanogens. These components are universal to $\mathrm{CH}_{4}$ production regardless of ecosystem type, hence questions focusing specifically on these controls potentially fall into the category of " $\mathrm{CH}_{4}$ ecology in streams." The second layer of the framework emphasizes the physical processes or structures that dictate where or when methanogenesis-appropriate conditions occur, or how $\mathrm{CH}_{4}$ may get delivered to the channel. Because hydrologic and geomorphic drivers have both direct indirect effects on $\mathrm{CH}_{4}$, their consideration may be germane to both the in and of approaches.

Before considering $\mathrm{CH}_{4}$ dynamics in the context of this conceptual framework, several comments and caveats are in order. First, the hierarchical nature of the model with distal controls acting on proximate drivers could be construed as a suggestion that the former set of controls operate across some larger or longer scale. However, we are not stipulating any specific spatial or temporal extent over which these drivers are apparent or relevant, and it is likely that these variables influence $\mathrm{CH}_{4}$ across multiple scales. Indeed, this framework does not explicitly address spatial or temporal dynamics, but instead the goal is to emphasize the web of controls and how their significance might vary in different times, places, or circumstances. Next, while there is growing evidence for methanogenesis in oxic freshwater habitats (Grossart et al. 2011, Bogard et al. 2014, Tang et al. 2014), numerous studies in streams and rivers highlight $\mathrm{CH}_{4}$ generation (e.g., Baker et al. 1999, Hlaváčová et al. 2005, Bonnett 


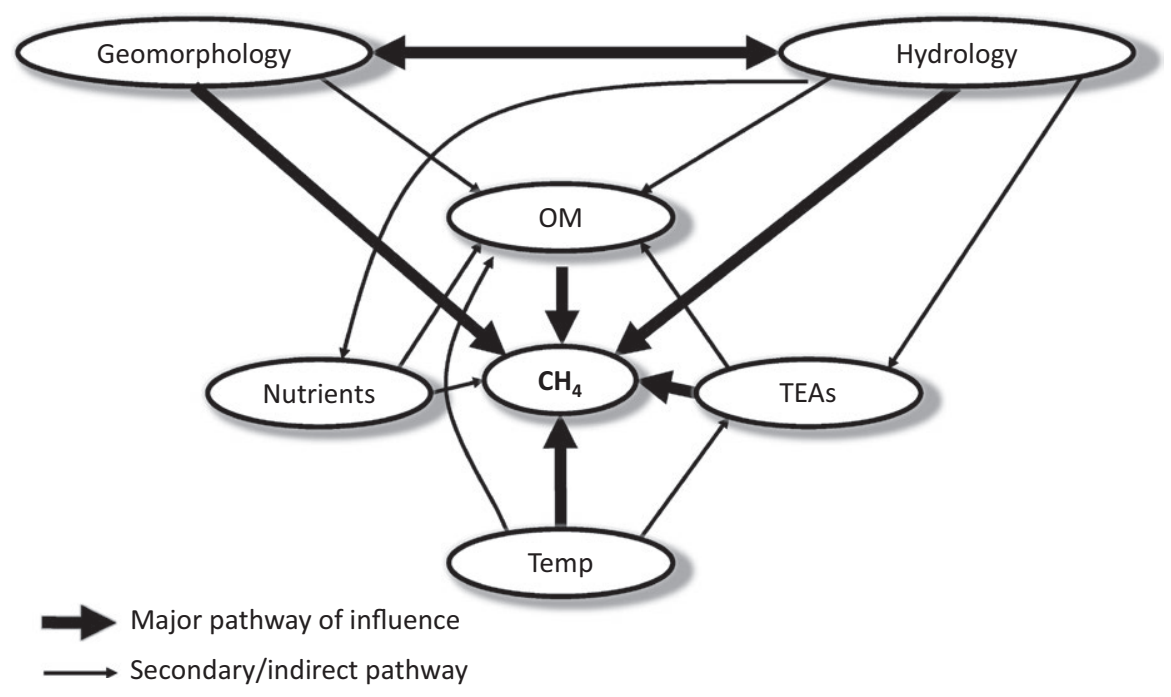

FIG. 8. Conceptual framework of controls on $\mathrm{CH}_{4}$ production and persistence in streams and rivers. Major pathways of influence are denoted by large arrows, while finer arrows represent secondary or indirect relationships. Proximate controls are those that can directly affect methane reactions: organic matter (OM), temperature (Temp), terminal electron acceptors (TEAs), and nutrients. Distal controls include geomorphology and hydrology.

et al. 2013, Shelley et al. 2015) and presence of methanogens (e.g., Porat et al. 2010, Buriánková et al. 2013) within anoxic sediments or saturated soils adjacent to the active channel. Hence, we assume that lotic methanogenesis is overwhelmingly anaerobic. Third, the role of nutrients as a proximate control has yet to be explored in lotic systems, so its inclusion in this framework is speculative and intended to provoke investigation. Fourth, this framework focuses on $\mathrm{CH}_{4}$ production, concentration, and flux. Less attention to is given to oxidation despite its potential to strongly affect the overall $\mathrm{CH}_{4}$ balance, reflecting the current state of the literature (discussed earlier). Fifth, some of the relationships shown in Fig. 8 are well grounded in the existing literature, while others are more tentative but we felt should be included as likely pathways of influence. Conversely, not all known relationships among drivers are included. For example, geomorphic heterogeneity (e.g., pool-riffle sequences or constrained and unconstrained valleys) can create differences in water temperature (Burkholder et al. 2008) or nutrient concentrations (Dent and Grimm 1999), which, in turn, have the potential to influence $\mathrm{CH}_{4}$ dynamics. However, these and other pathways were omitted because of an expectation of a relatively small influence on $\mathrm{CH}_{4}$. This decision points to the final critical constraint, which is that this framework should be viewed as a hypothesis that we hope will be tested and revised as research on this topic develops.

\section{Proximate controls}

Because the proximate influences identified in Fig. 8 represent basic controls on methanogenesis and are not unique to streams and rivers, there should be common- alities across disparate aquatic systems and opportunities to gain insights from cross-ecosystem comparisons. Below, we review the state of knowledge regarding these proximate controls in streams and rivers, highlight compelling findings from wetland and lake studies, and suggest potential avenues for future investigation.

Organic matter.-We begin the consideration of determinants of $\mathrm{CH}_{4}$ with $\mathrm{OM}$ based on the rationale that $\mathrm{OM}$ is the essential ingredient for determining whether or not methanogenesis can even occur in streams and rivers. $\mathrm{CH}_{4}$-generating habitats in lakes and wetlands, as well as streams and rivers, share a common trait of having ample stocks of OM that provide the fuel for respiration and allow this process to progress to the point when methanogenesis is the only remaining option. $\mathrm{CH}_{4}$ concentrations and fluxes are often correlated with sediment OM content (e.g., Wu et al. 2007, Baulch et al. 2011a, Crawford et al. 2014b), and analysis of MethDB revealed a positive relationship between concentration and DOC (Fig. 7). $\mathrm{CH}_{4}$ generation can be enhanced by addition of acetate (Baker et al. 1999) as well as natural sources of allochthonous (Tam et al. 1981) or autochthonous (Jones et al. 1995) OM. OM availability is arguably the first constraint to have been identified in early studies of rivers receiving sewage effluents (Moens 1957, Zaiss and Kaltwasser 1979, Berger and Heyer 1989), and waste inputs continue to be associated with elevated $\mathrm{CH}_{4}$ concentrations (e.g., Lilley et al. 1996, Garnier et al. 2013), particularly in locations with limited wastewater infrastructure (e.g., Purvaja and Ramesh 2001, Yang et al. 2012, Marwick et al. 2014). But beyond recognizing that increases in the quantity and distribution of OM-rich sediments can favor methanogenesis, questions 
regarding how the composition of the $\mathrm{OM}$ pool (beyond simple categories of labile and refractory) influence this process in streams and rivers have, to the best of our knowledge, yet to be considered.

Lessons from wetlands suggest possible avenues for investigations regarding relationships between OM and methanogenesis. For example, some humic substances may be capable of serving as alternative TEAs (Lovley et al. 1996, Keller et al. 2009, Smemo and Yavitt 2011) yet others can be toxic to methanogens (Minderlein and Blodau 2010), and therefore might decrease $\mathrm{CH}_{4}$ production in some OM-rich drainages. While there is no evidence of low or suppressed $\mathrm{CH}_{4}$ production apparent in the current stream literature, considering if and how OM quality interacts with stream $\mathrm{CH}_{4}$ dynamics is an open question, and may be particularly salient in high-latitude C-rich peatland drainages or in human-dominated sites where DOC quality may be greatly modified (Stanley et al. 2012, Hosen et al. 2014).

A second lesson from wetlands is the often-positive relationship between vascular plant production and $\mathrm{CH}_{4}$ emissions. Macrophytes provide labile $\mathrm{OC}$ to microbes and plant-mediated gas transport to the atmosphere reduces opportunities for $\mathrm{CH}_{4}$ oxidation (reviewed by Megonigal et al. 2004, Bridgham et al. 2013). Few studies have explored $\mathrm{CH}_{4}-$ macrophyte relationship in streams, but those that have confirm the positive influence of plants both on sedimentary $\mathrm{CH}_{4}$ pools (e.g., Sanders et al. 2007, Heffernan et al. 2008) and the efficient transport of $\mathrm{CH}_{4}$ to the atmosphere (Sanders et al. 2007, Wilcock and Sorrell 2008). In addition to these functions, vascular plants also facilitate the trapping and accumulation of fine OMrich sediments that support methanogenesis in streams (Sanders et al. 2007, Heffernan et al. 2008, Wilcock and Sorrell 2008). In one case, $\mathrm{CH}_{4}$ production may have been promoted not only by greater availability of OM associated with roots of alder trees growing in mid-channel islands, but also by $\mathrm{N}$ fixation within the rooting zone (Clilverd et al. 2008). Regardless of the mechanism, macrophytes and channel-associated trees are likely to play a substantial role in dictating stream $\mathrm{CH}_{4}$ dynamics, so when and where these organisms are present, they should be incorporated into stream and river studies.

Temperature.-The temperature dependence of methanogenesis (e.g., Nozhevnikova et al. 1997, Treat et al. 2014) provides a clear opportunity for cross-ecosystem analysis. Yvon-Durocher et al. (2014) argued that the temperature dependence of $\mathrm{CH}_{4}$ efflux is remarkably similar across different levels of biological organization and ecosystems, including rivers, and that, under controlled conditions, this process shows greater temperature sensitivity than gross primary production or ecosystem respiration (Yvon-Durocher et al. 2011). Yet the reality is that the relationship between water temperature and $\mathrm{CH}_{4}$ concentration and/or flux in streams and rivers is ambiguous. Some studies have found temperature to be strongly correlated with $\mathrm{CH}_{4}$ (e.g.,
Campeau and del Giorgio 2014) while others have identified it as a secondary or weak predictor (Dinsmore et al. 2013, Wallin et al. 2014; Fig. 6) or failed to find any relationship at all (e.g., Hope et al. 2001, Hlaváčová et al. 2006). In temperate and boreal settings, seasonal cycles of high summer/low winter $\mathrm{CH}_{4}$ concentrations or fluxes are both present (Dinsmore et al. 2013) and absent (Dawson et al. 2004); in one case, greatest concentrations and over half of the annual emission of $\mathrm{CH}_{4}$ occurred during winter (Silvennoinen et al. 2008). These results are perhaps not surprising, as the thermal influence does not act in isolation in any ecosystem (see also Trimmer et al. 2012) and reminds us of the need for caution with respect to extrapolations based on a single parameter.

Terminal electron acceptors.-The availability of different TEAs affects both rates and pathways by which $\mathrm{OM}$ is decomposed in aquatic ecosystems. Presence of more energetically favorable TEAs should suppress $\mathrm{CH}_{4}$ production, and this thermodynamic phenomenon has been documented for $\mathrm{Fe}^{3+}, \mathrm{NO}_{3}{ }^{-}$, and $\mathrm{SO}_{4}{ }^{2-}$ in wetlands (e.g., Roden and Wetzel 1996, Gauci et al. 2004). Jones et al. (1994) hypothesized that the vertical stratification of respiratory products observed in lake sediments due to the progressive reductions in energy yields of different respiratory pathways (Lovley and Klug 1986) would also be observed in streams, but stretched out longitudinally along subsurface flow paths. Thus, $\mathrm{CH}_{4}$ generation was predicted to occur only after abundant TEAs (i.e., $\mathrm{O}_{2}$, $\mathrm{NO}_{3}^{-}$, and $\mathrm{SO}_{4}{ }^{-2}$ ) were sequentially depleted as water traveled through channel bed sediments. Tests of this "thermodynamic constraints" hypothesis have yielded mixed results. Predictable patterns along flow paths have been observed at the riparian soil-stream interface (Hedin et al. 1998, Werner et al. 2012) and temporally over a diel cycle in the water column of a highly eutrophic agricultural canal (Harrison et al. 2005), but not within hyporheic sediments of some streams (Baker et al. 1999, Hlaváčová et al. 2005). Co-occurrence of different respiratory pathways has been considered a product of the heterogeneity of sedimentary and hydrologic conditions within benthic and hyporheic zones (Morrice et al. 2000, Clilverd et al. 2008). That is, distinct flow paths along which the predicted TEA sequence might be seen can be blurred by mixing of multiple flow paths or interrupted by local patches of fine sediments that support different rates or types of respiration (Werner et al. 2012). Finally, there is also increasing recognition that the "redox ladder" may not be as hierarchical as originally thought, particularly at the bottom end; for example, evidence from groundwater systems indicates that methanogenesis can be as energetically favorable as $\mathrm{Fe}^{3+}$ or $\mathrm{SO}_{4}^{2-}$ reduction under certain circumstances (Bethke et al. 2011). The net result is that, in aquatic environments with complex spatial distributions of TEAs and redox conditions, many anaerobic processes occur simultaneously (Baker et al. 1999, Smemo and Yavitt 2011, Bridgham et al. 2013). In our framework, 
we still expect the distribution and abundance of TEAs to influence $\mathrm{CH}_{4}$ dynamics in lotic systems. However, the conventional "redox ladder" ideology may not suffice in all circumstances and simple spatial patterns of electron acceptors may be hard to find in streams and rivers.

Nutrients.-As noted at the start of this section, considering if and how nutrients influence $\mathrm{CH}_{4}$ dynamics in streams and rivers has attracted little attention, particularly with respect to direct effects, so its inclusion is speculative. Two mechanisms of direct nutrient influence have been described in other aquatic settings. First, various wetland studies indicate that both $\mathrm{CH}_{4}$ producers and oxidizers can be nutrient limited (Bodelier and Steenbergh 2014). Second, $\mathrm{CH}_{4}$ production has been linked to $\mathrm{P}$ cycling in marine systems (Karl et al. 2008). Under conditions of extreme phosphorus (P) limitation, $\mathrm{CH}_{4}$ can be produced under aerobic conditions as a byproduct of methylphosphonate decomposition, and this process may also be enhanced by in situ $\mathrm{N}$ fixation. But if and how any of these specific pathways translate to streams and rivers remains to be seen.

While direct pathways of nutrient influence are yet to be examined in streams and rivers, the indirect pathway of nutrient limitation of GPP and ER that in turn affects autochthonous OM availability has received at least some attention. This pathway of nutrient influence is apparent in lakes, as eutrophic systems can have higher $\mathrm{CH}_{4}$ concentrations and fluxes than less productive, nutrient-poor sites (Ortiz-Llorente and Alvarez-Cobelas 2012, PalmaSilva et al. 2013). Further, addition of algal-derived OC to both stream (Jones et al. 1995) and lake (West et al. 2012) sediments stimulates methanogenesis, suggesting that if algal productivity is nutrient limited, then $\mathrm{N}$ and/ or $\mathrm{P}$ availability can indirectly affect $\mathrm{CH}_{4}$ production. As a related mechanism of nutrient influence associated with metabolism, eutrophication often results in large daily dissolved oxygen excursions and thus can influence the extent of oxygen-poor habitats. In one extreme example, the water column of a drainage canal in an intensive agricultural landscape shifted from supersaturation of up to $300 \%$ during the day to anoxia at night, eventually resulting in an increase in water column $\mathrm{CH}_{4}$ in the later stages of the night (Harrison et al. 2005).

Despite indications that nutrient enrichment is likely to enhance $\mathrm{CH}_{4}$ production, tests of this influence have not yielded clear-cut results. Relationships between nutrients and $\mathrm{CH}_{4}$ concentrations from MethDB were generally weak (SRP) or absent $\left(\mathrm{NO}_{3}^{-}\right.$; see Fig. 6). In wetland nutrient amendment experiments, $\mathrm{P}$ additions have been shown to increase, have no effect, or even inhibit $\mathrm{CH}_{4}$ production or evasion (Keller et al. 2006, Song et al. 2012, Veraart et al. 2015), and the same holds for $\mathrm{N}$ enrichment experiments (cf. Aerts and de Caluwe 1999, Granberg et al. 2001, Song et al. 2013). Multiple mechanisms have been suggested for these diverse responses, with site-specific attributes such as wetland type or nutrient status emerging as important determinants of experimental outcomes.
Nitrate is unusual in its dual role as a nutrient and a TEA. While addition of $\mathrm{NO}_{3}{ }^{-}$may relieve nutrient limitation and thus enhance $\mathrm{CH}_{4}$ production as described earlier in this section, its role as an energetically more favorable TEA should have the opposite effect. (e.g., Dodla et al. 2009, McCrackin and Elser 2011). But the relationship between $\mathrm{CH}_{4}$ and $\mathrm{N}$ is more complicated than this. Methanogens can fix N, nitrifiers can oxidize $\mathrm{CH}_{4}, \mathrm{CH}_{4}$ oxidation can be driven by denitrification, and different inorganic $\mathrm{N}$ fractions are toxic to methanogens (see reviews by Megonigal et al. 2004, Bodelier and Steenbergh 2014). The ecological significance of many of these relationships has yet to be explored in detail in aquatic settings, but the existence of multiple and often orthogonal pathways is consistent with the diverse outcomes of fertilization experiments noted in the previous paragraph. Given the increasing entanglement between $\mathrm{C}$ and $\mathrm{N}$ cycles associated with human activities, these $\mathrm{N}-\mathrm{CH}_{4}$ relationships are drawing significant attention among terrestrial and wetland ecologists (Bodelier and Steenbergh 2014). Of particular interest is the net effect of increased inorganic $\mathrm{N}$ supplies on the balance between $\mathrm{C}$ sequestration and $\mathrm{CH}_{4}$ emissions (along with other GHGs) in upland and wetland soils (Liu and Greaver 2009, Aronson and Helliker 2010). While the issue of C sequestration by lotic primary producers does not even begin to approach to the same level of global significance as it does for terrestrial and wetland ecosystems, the general issue of how nutrient enrichment alters the ratio of production vs. respiration, as well as the balance among different respiratory pathways, is equally germane to streams and rivers. Indeed, while $\mathrm{C}$ sequestration may be a non-issue, the unexpectedly high fluxes of $\mathrm{CO}_{2}$ (Raymond et al. 2013), $\mathrm{N}_{2} \mathrm{O}$ (Baulch et al. 2011b, Beaulieu et al. 2011), as well as $\mathrm{CH}_{4}$ (this study) from streams and rivers underscore the need to understand exactly if and how nutrient enrichment alters the relative contributions of different respiratory pathways within, and net GHG emissions from fluvial systems.

\section{Distal controls}

While the proximate controls considered here are relevant to methanogenesis in any aquatic environment, the second-level drivers in our framework emphasize distinctly fluvial phenomena. Hydrology and geomorphology are broad terms used here to encapsulate several pathways of influence on $\mathrm{CH}_{4}$ that focus on physical attributes and processes of stream and river channels (i.e., not upland environments). And as with proximate influences, these drivers are not independent of one another. Distinguishing between the effects of hydrology and geomorphology on lotic ecological processes is difficult in general, and $\mathrm{CH}_{4}$ is no exception. Nonetheless, two themes emerge from the literature: the influence of hydrologic delivery or dilution of $\mathrm{CH}_{4}$ or the raw materials needed for its generation, and how $\mathrm{CH}_{4}$ distribution is shaped by the geomorphic template of the channel. 
Hydrology.-Given its strict redox requirements, the reality is that methanogenesis within stream or river channels may proceed at a low rate, or in very few locations, or not at all. But hydrologic linkage to suitable habitats can deliver $\mathrm{CH}_{4}$ to the channel, and in fact, many studies point to $\mathrm{CH}_{4}$ production outside the active channel boundaries. Examples of hydrologic linkages that deliver $\mathrm{CH}_{4}$ include shallow groundwater flows that travel from saturated soils or peat deposits to the channel (Jones and Mulholland 1998a, Hope et al. 2001, Crawford et al. 2014b), water passing through hyporheic sediments (Baker et al. 1994, Schindler and Krabbenhoft 1998, Anthony et al. 2012), and connection to inundated floodplains (Richey et al. 1988, Pulliam 1993, Teodoru et al. 2015) or adjacent wetlands (Crawford et al. 2013, Bresney et al. 2015). Focused groundwater discharge can create small-scale spatial heterogeneity in $\mathrm{CH}_{4}$ (Jones and Mulholland 1998a, Hope et al. 2001), but largerscale patterns may also emerge associated with gradual changes in the relative contribution of groundwater that occur along a river continuum (Jones and Mulholland 1998b).

While spatial heterogeneity created by hydrology is apparent in many studies, temporal changes in flow can also have pronounced effects on delivery and/or persistence of $\mathrm{CH}_{4}$. Inverse relationships between discharge and $\mathrm{CH}_{4}$ concentration exist among vastly different sites, from small headwater catchments in peat-dominated landscapes (Hope et al. 2001, Dinsmore et al. 2013) to large temperate and tropical rivers (Koné et al. 2010, Anthony et al. 2012, Bouillon et al. 2014). Low concentrations during high-flow periods have been attributed to precipitation or snowmelt-driven dilution, increased gas exchange, and reduced sediment-water contact. More finely resolved temporal studies suggest that $\mathrm{CH}_{4}$ can follow a "first flush" behavior, with large fluxes preceding peak snowmelt discharge (Dyson et al. 2011), likely due to a washing out of $\mathrm{CH}_{4}$ that accumulated under snow and ice over winter (Campeau et al. 2014). These hydrologic pulses can also push out other solutes that have accumulated over winter, including labile DOC, which could potentially support a corresponding pulse of methanogenesis in C-limited stream sediments (Baker et al. 2000). In other situations, flood peaks have been associated with $\mathrm{CH}_{4}$ maxima, as high flows inundate and connect rivers to adjacent floodplains to enhance floodplain $\mathrm{CH}_{4}$ production and delivery to the main channel (Richey et al. 1988, Pulliam 1993). In one case, overland flooding connected a stream to surrounding wetlands, triggering a concentration increase of $>600 \times$ (Gatland et al. 2014). Collectively, these examples highlight a shared behavior across rivers of flow regime shaping the $\mathrm{CH}_{4}$ regime, but they also demonstrate the difficult reality that exactly how this influence plays out differs markedly among sites.

Geomorphology.-Correspondence between $\mathrm{CH}_{4}$ and geomorphology are most commonly explained in terms of either how the geomorphic template determines the distribution of flow paths that deliver methane to the channel (e.g., Jones and Mulholland 1998a), or with respect to presence/absence of sediment patches capable of supporting methanogenesis. In both cases, the strong tendency is to highlight spatial variation in geomorphic structure and its effect on $\mathrm{CH}_{4}$ while ignoring temporal variability. In the former case, spatial patterns in $\mathrm{CH}_{4}$ associated with groundwater inputs (discussed in the previous section on Hydrology) have, for example, been linked to spatial differences in geomorphic features such as differences in parent geology (Jones and Mulholland 1998a), bedrock fractures (Heilweil et al. 2015), or thermokarsts (Crawford et al. 2013). Effects of sediment composition on $\mathrm{CH}_{4}$ also tend to focus on spatial patterns, though over a broader range of scales. At relatively small scales, hotspots of methanogenesis and ebullition are associated with deposits of fine, OM-rich sediments (e.g., Sanders et al. 2007, Baulch et al. 2011a, Sawakuchi et al. 2014). Sediment and corresponding $\mathrm{CH}_{4}$ differences are also apparent at the larger reach and segment scales (sensu Frissell et al. 1986). Channel modifications by beavers (Castor canadensis and C. fiber) represent a particularly overt example, as sediment trapping caused by damming promotes methanogenesis (Yavitt et al. 1992, Roulet et al. 1997, Lazar et al. 2014). In one case, evasion rates in beaver ponds were 33 -fold greater than those in adjacent undammed reaches (Ford and Naiman 1988). Thus, the recent resurgence and spread of beaver are likely causing substantial increases in emissions across large continental areas of North America and Eurasia (Whitfield et al. 2015). Similar to beaver pond formation, rapid development of wetland-like reaches that accumulated fine, OM-rich sediments within a desert stream following removal of cattle promoted methanogenesis in the hyporheic zone (Heffernan et al. 2008). Yet other shifts in channel form, including presence of upstream lakes embedded within drainages (Crawford et al. 2014a), or pool-riffle sequences (Harrison et al. 2012) have not been associated with differences in $\mathrm{CH}_{4}$ distribution.

Accumulation of the fine sediments critical for inchannel $\mathrm{CH}_{4}$ production is greatest in low-gradient reaches where reduced water velocities promote particle deposition over transport or mobilization. Channel slope also exerts another critical direct control on $\mathrm{CH}_{4}$ by affecting gas exchange (Raymond et al. 2012). Because deposition of fine materials and reduction of gas exchange both occur in low-gradient channel sections and both favor $\mathrm{CH}_{4}$ accumulation, it is difficult to separate out the relative importance of these two mechanisms (Bresney et al. 2015). And as with patterns of sediment distribution, topographic effects on gas exchange can occur at scales of just a few meters in association with short, steep, channel sections with high reaeration rates (Lilley et al. 1996) to more drawn out longitudinal shifts in the channel profile occurring over several kilometers (Butman and Raymond 2011).

As noted above, studies considering geomorphic influences have consistently emphasized how spatial variation 
in the physical template creates heterogeneous patterns in $\mathrm{CH}_{4}$ concentrations and/or fluxes. Yet rivers are dynamic environments that are constantly shifting and adjusting at multiple spatial and temporal scales. Missing from our current understanding are the consequences of these temporal geomorphological dynamics for $\mathrm{CH}_{4}$ biogeochemistry (but see Sanders et al. 2007). An unacknowledged assumption in the vast majority of studies is that the time scales of $\mathrm{CH}_{4}$-relevant geomorphic change are extremely long: perhaps centuries to millennia or longer. Yet examples such as beaver pond proliferation over the past decade or seasonal accumulations of sediments highlight shorter time frames over which geomorphic conditions shift and affect $\mathrm{CH}_{4}$. Recognizing such temporal variability emphasizes hydrology as a driver of geomorphology rather than the current situation in which geomorphology is viewed as a fixed constraint on the distribution of flow paths. Focusing on geomorphic change over time also leads to questions about responses to disturbance and flow regime. For example, how are rates of methanogenesis affected by redistribution of sediments following floods? Do these disturbances enhance or suppress anaerobic metabolism, and if so, what determines subsequent response trajectories for $\mathrm{CH}_{4}$ following disturbance?

\section{Methane in a Changing World}

Human activities have multiple well-known effects on streams and rivers (Vörösmarty et al. 2010), leading some to consider them among the world's most degraded ecosystems (Carpenter et al. 2011). Inevitably, these pervasive changes are influencing fluvial $\mathrm{CH}_{4}$ dynamics, but understanding and estimating where, when, how, or how much are particularly challenged by limited investigation. Here, we consider two examples of anthropogenic activities and how they influence $\mathrm{CH}_{4}$, both because of their contemporary relevance and to demonstrate that changes in concentrations and fluxes can be evaluated in terms of shifting pathways of influence among the six proximate and/or distal controls of Fig. 8. That is, the conceptual framework can be reconfigured as alternative models or hypotheses to investigate mechanisms of change in methanogenesis following ecosystem alteration.

\section{Damming}

Impoundments represent an ambiguous boundary between lentic and lotic ecosystems, and historically have fallen into the gap between lake- and river-focused research. However, this deficit is diminishing with increasing recognition of the abundance and significance of these habitats to rivers, regional biogeochemical processing, and even global climate phenomena (Smith et al. 2002, Nilsson et al. 2005, Tranvik et al. 2009). This is certainly the case for $\mathrm{CH}_{4}$. Early studies of $\mathrm{CH}_{4}$ production and release from beaver ponds (e.g., Ford and Naiman 1988, Yavitt et al. 1990, Naiman et al. 1991) and lakes (e.g., Rudd and Hamilton 1978, Fallon et al. 1980) may have alerted investigators to the possible trade-off between "clean" (low GHG emissions) energy production by hydropower vs. GHG release by reservoirs (see review by Hertwich 2013).

Impoundment promotes $\mathrm{CH}_{4}$ production through two mechanisms that alter the extent of appropriate habitat for this process. First, reduced flow velocity allows the accumulation of sediments (hydrology $\rightarrow$ geomorphology pathway) and development of anoxic layers within reservoirs (hydrology $\rightarrow$ TEA pathway) to create habitat for methanogenesis. In addition to the influence of sediment accumulation, the shape of the impounded area (valley geomorphology) also comes into play in its influence on sediment trapping efficiency (Frenette and Julien 1996, Tamene et al. 2006), extent of the anoxic habitat, and inundated area. Second, flooding of terrestrial areas provides access to additional organic matter (hydrology $\rightarrow$ OM) following dam closure (Matthews et al. 2005, Venkiteswaran et al. 2013). Thermal regimes in reservoirs often depart from those of unimpounded reaches, but the strength and direction of this change is a function of site-specific conditions (Poff and Hart 2002, Kerimoglu and Rinke 2013), making generalization difficult.

Reservoirs consistently support concentrations and emission of $\mathrm{CH}_{4}$ that exceed those of upstream reaches of the same river, and on average, from natural lakes (St. Louis et al. 2000). These trends appear to hold across a range of impoundment sizes, from small run-of-river habitats in headwaters to massive reservoirs with multiyear hydrologic residence times. Areal fluxes vary over several orders of magnitude, and are positively related to terrestrial production and the correlated variable of latitude, and negatively related to energy density (energy produced per unit area of reservoir) and reservoir age (Barros et al. 2011, Hertwich 2013). Decomposition of terrestrial materials can lead to very high fluxes of $\mathrm{CH}_{4}$ as well as $\mathrm{CO}_{2}$ during the first few years of impoundment (Kelly et al. 1997), followed by a decline in emissions over time (Barros et al. 2011, Hertwich 2013). However, the consequences of aging may be more complicated than suggested by these studies, particularly for the myriad small impoundments that are common in headwater drainages throughout the world. As these more diminutive yet more abundant systems age, they undergo a successional process of infilling and habitat conversion in which the end stage is often an organic-rich flow-through wetland embedded within the riverine network (Powers et al. 2013) that is likely to support high rates of $\mathrm{CH}_{4}$ production and evasion. Indeed, the role and contribution of small run-of-river impoundments, regardless of their age, are not well quantified despite clear indications that they are particularly active sites of $\mathrm{CH}_{4}$ production (Maeck et al. 2013).

\section{Agricultural land use}

Almost $40 \%$ of the world's terrestrial land surfaces have been co-opted for agricultural use (Foley et al. 
2011) and in the United States, it is the leading cause of stream impairment (EPA 2012). While farming practices are remarkably diverse, common consequences for streams and rivers include nutrient enrichment and increased sediment loading. Agricultural effects on aquatic $\mathrm{C}$ cycling are beginning to receive more attention (Graeber et al. 2012, Stanley et al. 2012), but few studies have investigated $\mathrm{CH}_{4}$ dynamics in systems that drain agricultural landscapes. Our framework of $\mathrm{CH}_{4}$ controls (Fig. 8) suggests that these hallmark increases in sediment and nutrients have both direct and indirect effects on lotic $\mathrm{CH}_{4}$ dynamics.

Land clearing, plowing, planting, and overgrazing have mobilized massive quantities of soil in agricultural regions throughout the world. The magnitude of these actions is stunning, as humans are now responsible for more soil movement than any other geological process (Hooke 2000). Soils routinely fill valley floors and channels, forming thick layers of often fine, C-rich materials on floodplains and stream beds (Knox 2006, Needelman et al. 2007, Glendell and Brazier 2014). Because of the relatively fine texture of these sediments, accumulations within active channels are prone to anoxia (Hancock 2002) and are likely to be able to support methanogenesis. That is, high rates of sediment loading, particularly in low-gradient channels characteristic of many agricultural landscapes, should relieve a primary constraint on methanogenesis: the availability of appropriate anoxic, OM-rich habitat for its generation. This prediction has been validated for a UK chalk stream where a 100 -fold increase in $\mathrm{CH}_{4}$ concentration accompanied the trapping of fine sediment derived from agricultural soils (Sanders et al. 2007), and in agricultural streams in Wisconsin, USA, fine sediment deposits were identified as sites capable of substantial $\mathrm{CH}_{4}$ generation (Crawford and Stanley 2016). Beyond these two examples, we can also point to multiple studies documenting stream bed clogging or smothering by fine sediments in agricultural areas (reviewed by Wood and Armitage 1997), increased denitrification rates following upland disturbances that infused bed sediments with fine materials (Solomon et al. 2009), and patterns of reduced redox conditions in fine sediments relative to coarser materials (Boulton et al. 1998). The two steps in this process are independently well established (agriculture leading to high inputs of fine OM-rich sediments; fine OM-rich sediment deposits supporting methanogenesis), so the leap to the hypothesis that agricultural activities enhance stream methanogenesis via this direct geomorphic pathway is not a large one despite the extremely limited documentation. However, altered sediment regimes are just one consequence of farming, and its net effect on methanogenesis must be considered with respect to other accompanying changes that occur in these systems.

The second pervasive consequence of agricultural land use is increased nutrient loading to aquatic ecosystems and as discussed earlier, this enrichment could have direct and indirect, positive and negative, effects on methanogenesis. Given that $\mathrm{NO}_{3}{ }^{-}$enrichment, often to remarkable levels, is a widespread feature of streams and rivers draining agricultural landscapes (e.g., Herlihy et al. 1998, Stanley and Maxted 2008, Sponseller et al. 2014), an obvious first avenue of investigation is to consider the balance between potential positive and negative effects of $\mathrm{NO}_{3}^{-}$. The simultaneous occurrence of multiple redox transformations in stream beds suggests that reduced $\mathrm{CH}_{4}$ concentrations and fluxes associated with greater $\mathrm{NO}_{3}^{-}$inputs are not necessarily a given for streams and rivers. Indeed, the absence of any relationship between $\mathrm{NO}_{3}{ }^{-}$and $\mathrm{CH}_{4}$ (Fig. 6) and the high concentrations and fluxes in agriculture/cropland areas from our database analysis (Figs. 4 and 5) point to agricultural activities as having an overall positive effect on net $\mathrm{CH}_{4}$ production.

Beyond changes in nutrient and sediment delivery, there are many other pathways of agricultural influence that have the potential to affect $\mathrm{CH}_{4}$ production. These include changes to flow, thermal, and light regimes (Scanlon et al. 2007, Julian et al. 2008, Webb et al. 2008); increased loads and changes in relative amounts of other TEAs (Palviainen et al. 2014); and changes in the amount, timing, and quality of OM loading (Graeber et al. 2012, Stanley et al. 2012, Kaushal et al. 2014). One additional widespread modification of particular relevance to aquatic sources of atmospheric $\mathrm{CH}_{4}$ is the widespread practice of ditching poorly drained soils to increase agricultural and silvicultural production, a geomorphic alteration that creates new lotic environments in the form of these drainage ditches at the expense of wetland habitat. Given the substantial and conflicting roles of saturated soils as sites of $\mathrm{C}$ storage as $\mathrm{OM}$ vs. $\mathrm{C}$ release to the atmosphere as $\mathrm{CO}_{2}$ and $\mathrm{CH}_{4}$, consequences of drainage are not immediately obvious in terms of its effect on net C and GHG balances (Laiho 2006). Attention to this issue has overwhelmingly been focused on wetland/soil processes without including the drainage ditches, and in some cases, fluxes from these new lotic habitats are indeed small (Minkkinen et al. 1997, Hyvönen et al. 2013). However, in others, ditch fluxes can exceed those from nearby undrained (Dyson et al. 2011, Luan and Wu 2015) or drained (Roulet and Moore 1995, Vermaat et al. 2011) soils, and may even account for the majority of the total efflux from an entire drained site (Schrier-Uijl et al. 2010). The latter suggests that, in some cases, ditching may simply shift the location of $\mathrm{CH}_{4}$ efflux from wetland soils to these engineered lotic habitats.

\section{Final remarks regarding methane in a changing world}

The goal of this exercise has been to illustrate how two widespread human activities may affect $\mathrm{CH}_{4}$ dynamics in lotic ecosystems by highlighting likely shifts in pathways of influence. And while we focused on these two prevalent human activities, other practices and consequences (e.g., logging, urbanization, pollutant inputs, even restoration) inevitably affect fluvial $\mathrm{CH}_{4}$ dynamics; how this happens should be traceable through our conceptual framework. 
A second, practical issue that we draw from this exercise is the indication that the net effect of these and other anthropogenic changes appears to be an enhancement of $\mathrm{CH}_{4}$ generation in, and efflux from fluvial systems. Further, land use changes and processes such as impoundment, sedimentation, and eutrophication that often favor $\mathrm{CH}_{4}$ enrichment are occurring against a backdrop of warming streams and rivers (Kaushal et al. 2010, Orr et al. 2015) that should also increase $\mathrm{CH}_{4}$ production. Other anthropogenic changes have yet to be considered in any meaningful way, including inputs of diverse cocktails of pollutants that include heavy metals, personal care products, pharmaceuticals, herbicides and pesticides, etc. Hydrocarbon pollution has been associated with substantial $\mathrm{CH}_{4}$ production and ebullition in rivers (McLinn and Stolzenburg 2009, Zhu et al. 2015), and often-elevated $\mathrm{CH}_{4}$ concentrations and fluxes in human-influenced streams do not suggest strong negative consequences of pollutants on methanogenesis. Clearly, longer-term and more spatially extensive measures and experiments are needed to rigorously evaluate the possibility that anthropogenic activities are leading to greater $\mathrm{CH}_{4}$ efflux from rivers and streams, and the significance of any increases in emissions needs to be considered in the context of changes in other sources to the atmosphere. Yet the early returns are notable in their consistent support for this hypothesis.

\section{Future Directions}

Our review has revealed several gaps and contradictory findings in the current understanding of $\mathrm{CH}_{4}$ in streams and rivers. But first, and perhaps most conspicuous of all, is the gap in data, despite the recent uptick in research activity. While we were able to identify several flux and concentration values, the number of studies is still remarkably small and the global distribution is uneven (Fig. 3). Our collation of 951 and 397 sites with concentration and diffusive flux values, respectively, pales in comparison to the 6708 observations of stream and river $p \mathrm{CO}_{2}$ used to develop a model of global riverine $\mathrm{CO}_{2}$ emissions (Raymond et al. 2013). Data constraints are most acute for efflux measurements; the pool of diffusive flux estimates is small, but more problematic is the virtual absence of information on ebullition. Given the wide range in the contribution of bubble-mediated $\mathrm{CH}_{4}$ losses to total efflux (from $0 \%$ to $95 \%$ for 27 cases in which both pathways were quantified), the remarkable spatial and temporal heterogeneity of this process (Crawford et al. $2014 b$ ), and the very small size of the available data pool ( $n=26$ unique sites; Table 1 ) we are uncomfortable with suggesting an estimate for this unmeasured pathway. Fortunately, new tools are emerging that should improve the capacity to quantify ebullition (e.g., see Maeck et al. 2013, DelSontro et al. 2015) and help address this conspicuous void. Beyond this data constraint, additional gaps in understanding $\mathrm{CH}_{4}$ in streams and rivers include the lack of direct measurements of methanogenesis and understanding of its contribution to ER, a remarkable scarcity of studies on vascular plant influence on $\mathrm{CH}_{4}$ dynamics, and a paucity of work on how the $\mathrm{CH}_{4}$ balance is affected by nutrient enrichment, among others.

As has been highlighted throughout the paper, the bulk of the current literature has been motivated by goals of quantifying streams as processors of OC and/ or sources of $\mathrm{C}$ gases, reflecting the substantial influence of Cole et al. (2007) and Bastviken et al. (2011). This is an extremely important research avenue, and is central to the fundamental shift in the perception of fluvial systems from being viewed as simple transporters of $\mathrm{C}$, or, at best, systems whose contribution to larger-scale $\mathrm{C}$-cycling is trivial, to a developing recognition of streams and rivers as active transformers and meaningful sources of GHGs. Nonetheless, this singular focus means that opportunities to consider $\mathrm{CH}_{4}$ ecology in streams and rivers and to use $\mathrm{CH}_{4}$ to gain insights about lotic ecosystem structure and function are underdeveloped and ripe for investigation. We draw the paper to a close by revisiting opportunities and questions that may be particularly promising.

\section{Heterogeneity of methane}

A theme that emerges from many studies included in this review is the substantial heterogeneity of $\mathrm{CH}_{4}$ concentrations and fluxes, particularly at fine spatial scales. A first-principles perspective emphasizes this same localized control. The solubility of $\mathrm{CH}_{4}$ in water is very low and gas exchange for streams and rivers is often high; as a result, the distance over which supersaturated $\mathrm{CH}_{4}$ is outgassed as water moves downstream is relatively short (10-1000 m; Lilley et al. 1996, Billett and Harvey 2013, Crawford et al. 2014a) and matches observations of pronounced heterogeneity in concentrations over these same spatial extents (e.g., Jones and Mulholland 1998b, Hope et al. 2001). Thus, $\mathrm{CH}_{4}$ detected at a particular point in a stream or river predominantly reflects local production and/or inputs that overcome its rapid loss to the atmosphere and/or oxidation.

Conceptual models of spatial variability in streams are framed by two contrasting perspectives. At one end are frameworks that emphasize flow as an integrator over space and downstream gradients of change, and at the other end are those that highlight patchiness and abrupt change. The tension between the homogenizing role of flow vs. heterogeneity associated with distinct patch structure is embodied in the River Continuum Concept (Vannote et al. 1980), which highlights discharge as an integrator and gradual gradients of change along the channel length, and patch dynamics models (e.g., Frissell et al. 1986, Townsend 1989) in which discrete breaks in pattern and process are emphasized (Montgomery 1999). In reality, stream attributes may shift between a gradual flow-integrated configuration ("routing control" sensu Montgomery 1999) to having a more variable and abrupt pattern (local control; e.g., see Valett et al. 2014). This same situation applies across solutes, with local influences becoming more apparent for compounds that 
are more reactive or subject to greater biological demand (Dent and Grimm 1999). The extreme redox position of $\mathrm{CH}_{4}$ coupled with its low solubility means that its distribution is dominated by localized controls- indeed, it is arguably one of the most locally controlled of all solutes of ecological significance. That is, we suggest that $\mathrm{CH}_{4}$ represents the end-member in the spectrum of local vs. routing processes that can be used as a reference point for considering the relative contribution of these two types of controls on other ecosystem properties.

\section{Anaerobic metabolism}

While stream and river ecology has a rich conceptual tradition focused on ecosystem metabolism and energy balance that has also informed the understanding of other ecosystems (e.g., Odum 1956, Fisher and Likens 1973, Vannote et al. 1980), anaerobic metabolism has not been part of this history. This leads to the basic question: do anaerobic pathways make significant contributions to energy flow and $\mathrm{C}$ balance in lotic ecosystems, and if so, under what conditions? Without a doubt, methodological constraints are part of this omission (and not just in streams; Keller and Bridgham 2007), along with conventional biases regarding the significance (or rather, the lack thereof) of anaerobic processes at the whole-ecosystem scale. But simply recognizing the pervasiveness of $\mathrm{CH}_{4}$ in these systems is a critical step forward, and substantial strides have been made in the past 2-3 yr in terms of documenting the occurrence of $\mathrm{CH}_{4}$ across broad spatial extents (e.g., Campeau et al. 2014, Sawakuchi et al. 2014, Selvam et al. 2014, Wallin et al. 2014, Borges et al. 2015). Technologies are rapidly improving for field-based measurement of this and other GHGs that should increase data availability and make determination of rates of anaerobic metabolism more tractable (e.g., Maher et al. 2013, Crawford et al. 2015). In the meantime, $\mathrm{CH}_{4}: \mathrm{CO}_{2}$ ratios provide a simple but effective tool for investigating the shifting contribution of anaerobic metabolism over space and time.

\section{Trophic dynamics}

The emphasis to date on export over in situ metabolic processes crystallizes a key issue regarding the "ecology of" vs. "ecology in" approaches. The recent return of attention to $\mathrm{CH}_{4}$ oxidation (Trimmer et al. 2012) was largely inspired by observations of invertebrates and fish with highly depleted ${ }^{13} \mathrm{C}$ signatures, which suggested $\mathrm{CH}_{4}$ incorporation into stream food webs via consumption of methanotrophic microbes (Kohzu et al. 2004). In some cases, $\mathrm{CH}_{4}$-derived $\mathrm{C}$ contributes up to $30 \%$ of macroinvertebrate biomass (Trimmer et al. 2009), and there are compelling arguments for including this unconventional energy source into conceptual models of aquatic food webs (Jones and Grey 2011). But the larger point here is that the dominant focus on the ecology of $\mathrm{CH}_{4}$ has meant that a potentially significant facet of energy flow and trophic dynamics in streams has been overlooked. Thus, the attempt to place methanogenesis within an ener- getic context has highlighted a remarkable knowledge gap regarding the significance of anaerobic pathways of metabolism in lotic ecosystems- a deficit that is only very slowly starting to be addressed (Trimmer et al. 2012).

\section{Conclusion}

Increasing the limited collection of studies of $\mathrm{CH}_{4}$ in streams and rivers should greatly sharpen the current understanding of the contribution of these ecosystems to the growing atmospheric $\mathrm{CH}_{4}$ pool and to larger-scale $\mathrm{C}$ cycles $\left(\mathrm{CH}_{4}\right.$ ecology of streams), as well as providing an opportunity to gain fresh ecological insights into issues such as the significance of anaerobic metabolism to energy flow and patterns and causes of spatial heterogeneity ( $\mathrm{CH}_{4}$ ecology in streams). Other conceptually rich areas for exploration include coupling of biogeochemical cycles (particularly of $\mathrm{CH}_{4}$ and N; Trimmer et al. 2012, Bodelier and Steenbergh 2014), understanding the significance of $\mathrm{CH}_{4}$ as an allochthonous subsidy in food webs, or how this locally controlled gas responds to different natural and anthropogenic disturbances. While more is known about the $\mathrm{CH}_{4}$ ecology of than in these ecosystems, current conceptual and data limitations highlight the need for studies from both directions, and that there is much to be learned about the dynamics of this ephemeral and paradoxical gas in streams and rivers.

\section{ACKNOWLEDGEMENTS}

We are very grateful to M. Baker, S. Bouillon, S. Bresney, E. Hertwich, N. Snyder, and C. Teodoru for providing additional information about their publications. Thanks also go to J. Rosentreter, S. Ruiz-Halpern, D. Maher, as well as M. Demarty, and V. Heilweil for generously sharing unpublished or supplemental methane data. M C. McAleavey assisted with data entry, and C. Gries provided substantial help with database development and logistics, and translated German publications. We thank A. Appling, J. Corman, K. Rose, R. Smith, and two anonymous reviewers for providing thoughtful comments that greatly improved this article. Support for this paper was provided by funding from the North Temperate Lakes LTER program, NSF DEB-0822700.

\section{Literature Cited}

Adams, D. D., and G. M. Simiyu. 2009. Greenhouse gas (methane and carbon dioxide) emissions from a tropical river in Kenya: the importance of anthropogenic factors on natural gas flux. Internationale Vereiningung für Theoretische und Angewandte Limnologie Verhandlungen 30:887-889.

Aerts, R., and H. de Caluwe. 1999. Nitrogen deposition effects on carbon dioxide and methane emissions from temperate peatland soils. Oikos 84:44-54.

Anthony, S. E., F. G. Prahl, and T. D. Peterson. 2012. Methane dynamics in the Willamette River, Oregon. Limnology and Oceanography 57:1517-1530.

Aronson, E. L., and B. R. Helliker. 2010. Methane flux in nonwetland soils in response to nitrogen addition: a meta-analysis. Ecology 91:3242-3251.

Aufdenkampe, A. K., E. Mayorga, P. A. Raymond, J. M. Melack, S. C. Doney, S. R. Alin, R. E. Aalto, and K. Yoo. 2011. Riverine coupling of biogeochemical cycles between land, oceans, 
and atmosphere. Frontiers in Ecology and the Environment 9:53-60.

Baker, M. A., C. N. Dahm, H. M. Valett, J. A. Morrice, K. S. Henry, M. E. Campana, and G. J. Wroblicky. 1994. Spatial and temporal variation in methane distribution at the ground water/ surface water interface in headwater catchments. Pages 29-37 in J. A. Stanford, and H. M. Valett, editors. Proceedings of the second international conference on ground water ecology, American Water Resources Association, Herndon, VA, USA.

Baker, M. A., C. N. Dahm, and H. M. Valett. 1999. Retention and metabolism in the hyporheic zone of a mountain stream. Limnology and Oceanography 44:1530-1539.

Baker, M. A., H. M. Valett, and C. N. Dahm. 2000. Organic carbon supply and metabolism in a shallow groundwater ecosystem. Ecology 81:3133-3148.

Barros, N., J. J. Cole, L. J. Tranvik, Y. T. Prairie, D. Bastviken, V. L. Huszar, P. del Giorgio, and F. Roland. 2011. Carbon emission from hydroelectric reservoirs linked to reservoir age and latitude. Nature Geoscience 4:593-596.

Bastviken, D., L. J. Tranvik, J. A. Downing, P. M. Crill, and A. Enrich-Prast. 2011. Freshwater methane emissions offset the continental carbon sink. Science 331:50.

Battin, T. J., S. Luyssaert, L. A. Kaplan, A. K. Aufdenkampe, A. Richter, and L. J. Tranvik. 2009. The boundless carbon cycle. Nature Geoscience 2:598-600.

Baulch, H. M., P. J. Dillon, R. Maranger, and S. Schiff. 2011a. Diffusive and ebullitive transport of methane and nitrous oxide from streams: are bubble-mediated fluxes important? Journal of Geophysical Research 116:G04028. doi:10.1029/2011JG001656.

Baulch, H. M., S. L. Schiff, R. Maranger, and P. J. Dillon. $2011 \mathrm{~b}$. Nitrogen enrichment and the emission of nitrous oxide from streams. Global Biogeochemical Cycles 25:GB4013. doi:10.1029/2011GB004047.

Beaulieu, J. J. 2007. Controls on greenhouse gas emissions from headwater streams. Dissertation. University of Notre Dame, Notre Dame, Indiana, USA.

Beaulieu, J. J., et al. 2011. Nitrous oxide emission from denitrification in stream and river networks. Proceedings of the National Academy of Sciences USA 108:214-219.

Berger, U., and J. Heyer. 1989. Untersuchungen zum Methankreislauf in der Saale. Journal of Basic Microbiology 29:195-213.

Bethke, C. M., R. A. Sanford, M. F. Kirk, Q. Jin, and T. M. Flynn. 2011. The thermodynamic ladder in geomicrobiology. American Journal of Science 311:183-210.

Billett, M. F., and F. H. Harvey. 2013. Measurements of $\mathrm{CO}_{2}$ and $\mathrm{CH}_{4}$ evasion from UK peatland headwater streams. Biogeochemistry 114:165-181.

Bodelier, P. L. E., and A. K. Steenbergh. 2014. Interactions between methane and the nitrogen cycle in light of climate change. Current Opinions in Environmental Sustainability 9-10:26-36.

Bogard, M. J., P. A. del Giorgio, L. Boutet, M. C. Garcia Chaves, and Y. T. Prairie. 2014. Oxic water column methanogenesis as a major component of aquatic $\mathrm{CH}_{4}$ fluxes. Nature Communications 5:5350. doi:10.1038/ncomms6350.

Bonnett, S. A. F., M. S. A. Blackwell, R. Leah, V. Cook, M. O'Connor, and E. Maltby. 2013. Temperature response of denitrification rate and greenhouse gas production in agricultural river margin wetland soils. Geobiology 11:252-267.

Borges, A. V., et al. 2015. Globally significant greenhouse-gas emissions from African inland waters. Nature Geoscience 8:637-642.

Borrel, G., D. Jézéquel, C. Biderre-Petit, N. Morel-Desrosiers, J.-P. Morel, P. Peyret, G. Fonty, and A.-C. Lehours. 2011.
Production and consumption of methane in freshwater lake ecosystems. Research in Microbiology 162:832-847.

Bouillon, S., A. Yambélé, D. P. Gillikin, C. Teodoru, F. Darchambeau, T. Lambert, and A. V. Borges. 2014. Contrasting biogeochemical characteristics of the Oubangui River and tributaries (Congo River basin). Scientific Reports 4:5402. doi:10.1038/srep05402.

Boulton, A. J., S. Findlay, P. Marmonier, E. H. Stanley, and H. M. Valett. 1998. The functional significance of the hyporheic zone in streams and rivers. Annual Review of Ecology and Systematics 29:59-81.

Bresney, S. R., S. Moseman-Valtierra, and N. P. Snyder. 2015. Observations of greenhouse gases and nitrate concentrations in a Maine river and fringing wetland. Northeastern Naturalist 22:120-143.

Bridgham, S. D., H. Cadillo-Quiroz, J. K. Keller, and Q. Zhuang. 2013. Methane emissions from wetlands: biogeochemical, microbial and modeling perspectives from local to global scales. Global Change Biology 19:1323-1346.

Buriánková, I., L. Brablcová, V. Mach, P. Dvořák, P. P. Chaudhary, and M. Rulík. 2013. Identification of methanogenic Archaea in the hyporheic sediment of Sitka stream. PLoS ONE 8:e80804 doi10.1371/journal.pone.0080804.

Burkholder, B. K., G. E. Grant, R. Haggerty, T. Khangaonkar, and P. J. Wampler. 2008. Influence of hyporheic flow and geomorphology on temperature of a large, gravel-bed river, Clackamas River, Oregon, USA. Hydrological Processes 22:941-953.

Bussmann, I. 2013. Distribution of methane in the Lena Delta and Buor-Khaya Bay, Russia. Biogeosciences 10:4641-4652.

Butman, D., and P. A. Raymond. 2011. Significant efflux of carbon dioxide from streams and rivers of the United States. Nature Geoscience 4:839-842.

Campeau, A., and P. A. del Giorgio. 2014. Patterns in $\mathrm{CH}_{4}$ and $\mathrm{CO}_{2}$ concentrations across boreal rivers: major drivers and implications for fluvial greenhouse emissions under climate change scenarios. Global Change Biology 20:1075-1088.

Campeau, A., J. F. Lapierre, D. Vachon, and P. A. del Giorgio. 2014. Regional contribution of $\mathrm{CO}_{2}$ and $\mathrm{CH}_{4}$ fluxes from the fluvial network in a lowland boreal landscape of Québec. Global Biogeochemical Cycles 28:57-69.

Carpenter, S. R., E. H. Stanley, and M. J. Vander Zanden. 2011. State of the world's freshwater ecosystems: physical, chemical, and biological changes. Annual Review of the Environment and Resources 36:75-99.

Chowdhury, T. R., and R. P. Dick. 2013. Ecology of aerobic methanotrophs in controlling methane fluxes from wetlands. Applied Soil Ecology 65:8-22.

Christensen, P. B., L. P. Nielsen, J. Sorensen, and N. P. Revsbech. 1990. Denitrification in nitrate-rich streams: diurnal and seasonal variation related to benthic oxygen metabolism. Limnology and Oceanography 35:640-651.

Clilverd, H. M., J. B. Jr Jones, and K. Kiell. 2008. Nitrogen retention in the hyporheic zone of a glacial river in interior Alaska. Biogeochemistry 88:31-46.

Cole, J. J., et al. 2007. Plumbing the global carbon cycle: integrating inland waters into the terrestrial carbon budget. Ecosystems 10:171-184.

Conrad, R. 2009. The global methane cycle: recent advances in understanding the microbial processes involved. Environmental Microbiology Reports 1:285-292.

Crawford, J. T., and E. H. Stanley. Controls on methane concentrations and fluxes in streams draining human-dominated landscapes. Ecological Applications doi:10.1890/15-1330

Crawford, J. T., R. G. Striegl, K. P. Wickland, M. M. Dornblaser, and E. H. Stanley. 2013. Emissions of carbon dioxide and methane from a headwater stream network of interior 
Alaska. Journal of Geophysical Research Biogeosciences 118:482-494.

Crawford, J. T., N. R. Lottig, E. H. Stanley, J. F. Walker, P. C. Hanson, J. C. Finlay, and R. G. Striegl. 2014a. $\mathrm{CO}_{2}$ and $\mathrm{CH}_{4}$ emissions from streams in a lake-rich landscape: patterns, controls, and regional significance. Global Biogeochemical Cycles 28:197-210.

Crawford, J. T., E. H. Stanley, S. A. Spawn, J. C. Finlay, L. C. Loken, and R. G. Striegl. 2014b. Ebullitive methane emissions from oxygenated wetland streams. Global Change Biology 20:3408-3422.

Crawford, J. T., L. C. Loken, N. J. Casson, C. Smith, A. G. Stone, and L. A. Winslow. 2015. High-speed limnology: using advanced sensors to investigate spatial variability in biogeochemistry and hydrology. Environmental Science \& Technology 49:442-450.

Dahm, C. N., D. L. Carr, and R. L. Coleman. 1991. Anaerobic carbon cycling in stream ecosystems. Internationale Vereiningung für Theoretische und Angewandte Limnologie Verhandlungen 24:1600-1604.

Dawson, J. J. C., M. F. Billett, C. Neal, and S. Hill. 2002. A comparison of particulate, dissolved, and gaseous carbon in two contrasting upland streams in the U.K. Journal of Hydrology 257:226-246.

Dawson, J. J. C., M. F. Billett, D. Hope, S. M. Palmer, and C. M. Deacon. 2004. Sources and sinks of aquatic carbon in a peatland stream continuum. Biogeochemistry 70:71-92.

de Angelis, M. A., and M. D. Lilley. 1987. Methane in surface waters of Oregon estuaries and rivers. Limnology and Oceanography 32:716-722.

de Angelis, M. A., and M. I. Scranton. 1993. Fate of methane in the Hudson River and estuary. Global Biogeochemical Cycles 7:509-523.

DelSontro, T., D. F. McGinnis, B. Wehrli, and I. Ostrovsky. 2015. Size does matter: importance of large bubbles and small-scale hot spots for methane transport. Environmental Science \& Technology 49:1268-1276.

Dent, C. L., and N. B. Grimm. 1999. Spatial heterogeneity of stream water nutrient concentrations over successional time. Ecology 80:2283-2298.

Dinsmore, K. J., M. F. Billett, and K. E. Dyson. 2013. Temperature and precipitation drive temporal variability in aquatic carbon and GHG concentrations and fluxes in a peatland catchment. Global Change Biology 19:2133-2148.

Dodla, S. K., J. J. Wang, R. D. Delaune, and G. Breitenbeck. 2009. Carbon gas production under different electron acceptors in a freshwater marsh soil. Chemosphere 76:517-522.

Dyson, K. E., M. F. Billett, K. J. Dinsmore, F. Harvey, A. M. Thomson, S. Piirainen, and P. Kortelainen. 2011. Release of aquatic carbon from two peatland catchments in E. Finland during the spring snowmelt period. Biogeochemistry 103:125-142.

Ellis, E. C., K. Klein Goldewijk, S. Siebert, D. Lightman, and N. Ramankutty. 2010. Anthropogenic transformation of the biomes, 1700 to 2000. Global Ecology and Biogeography 19:589-606.

EPA. 2012. Watershed assessment, tracking and environmental results. National summary of state information reporting year 2012. U.S. Environmental Protection Agency. http://ofmpub. epa.gov/waters10/attains_index.control

Etiope, G., and R. W. Klusman. 2002. Geologic emissions of methane to the atmosphere. Chemosphere 49:777-789.

Fallon, R. D., S. Harrits, R. S. Hanson, and T. D. Brock. 1980. The role of methane in internal carbon cycling in Lake Mendota during summer stratification. Limnology and Oceanography 25:357-360.
Finlay, J. C. 2003. Controls on streamwater dissolved inorganic carbon dynamics in a forested watershed. Biogeochemistry 62:231-252.

Fisher, S. G. 1997. Creativity, idea generation, and functional morphology of streams. Journal of the North American Benthological Society 16:305-318.

Fisher, S. G., and G. E. Likens. 1973. Energy flow in Bear Brook, New Hampshire: an integrative approach to stream ecosystem metabolism. Ecological Monographs 43:421-439.

Flessa, H., A. Rodionov, G. Goggenberger, H. Fuchs, P. Magdon, O. Shibistova, G. Zrazhevskaya, N. Mikheyeva, O. A. Kasansky, and C. Blodau. 2008. Landscape control of $\mathrm{CH}_{4}$ fluxes in a catchment of the forest tundra ecotone of northern Siberia. Global Change Biology 14:2040-2056.

Foley, J. A., et al. 2011. Solutions for a cultivated planet. Nature 478:337-342.

Ford, T. E., and R. J. Naiman. 1988. Alteration of carbon cycling by beaver: methane evasion rates from boreal forest streams and rivers. Canadian Journal of Zoology 66:529-533.

Forster, P., et al. 2007. Changes in atmospheric constituents and in radiative forcing. Pages 129-234 in S. Solomon, D. Qin, M. Manning, Z. L. Chen, M. Marquis, K. B. Averyt, M. M. B. Tignor, and H. L. Miller, editors. Climate change 2007: the physical science basis. Contribution of Working Group I to the Fourth Assessment Report of the Intergovernmental Panel on Climate Change. Cambridge University Press, Cambridge, UK..

Frenette, M., and P. Y. Julien. 1996. Physical processes governing reservoir sedimentation. Pages 121-142 in Proceedings of the International Conference on Reservoir Sedimentation. Volume 1. Colorado State University, Fort Collins, Colorado, USA.

Frissell, C. A., W. J. Liss, C. E. Warren, and M. D. Hurley. 1986. A hierarchical framework for stream habitat classification: viewing streams in a watershed context. Environmental Management 10:199-214.

Garnier, J., G. Vilain, M. Silvestre, G. Billen, S. Jehanno, D. Poirier, A. Martinez, C. Decuq, P. Cellier, and G. Abril. 2013. Budget of methane emissions from soils, livestock and the river network at the regional scale of the Seine basin (France). Biogeochemistry 116:199-214.

Gatland, J. R., I. R. Santos, D. T. Maher, T. M. Duncan, and D. V. Erler. 2014. Carbon dioxide and methane emissions from an artificially drained coastal wetland during a flood: implications for wetland global warming potential. Journal of Geophysical Research: Biogeosciences 119:1698-1716.

Gauci, V., E. Matthews, N. Dise, B. Walter, D. Koch, G. Granberg, and M. Vile. 2004. Sulfur pollution suppression of the wetland methane source in the 20th and 21st centuries. Proceedings of the National Academy of Sciences USA 101:12583-12587.

Glendell, M., and R. E. Brazier. 2014. Accelerated export of sediment and carbon from a landscape under intensive agriculture. Science of the Total Environment 476-477: 643-656.

Graeber, D., J. Gelbrecht, M. T. Pusch, C. Anlanger, and D. von Schiller. 2012. Agriculture has changed the amount and composition of dissolved organic matter in Central European headwater streams. Science of the Total Environment 438:435-446.

Granberg, G., I. Sundh, B. H. Svensson, and M. Nilsson. 2001. Effects of temperature, and nitrogen and sulfur deposition, on methane emission from a boreal mire. Ecology 82:1982-1998.

Grossart, H.-P., K. Frindte, C. Dziallas, W. Eckert, and K. W. Tang. 2011. Microbial methane production in oxygenated 
water column of an oligotrophic lake. Proceedings of the National Academy of Sciences USA 108:19657-19661.

Guérin, F., G. Abril, D. Serça, S. Richard, R. B. Burban, C. Reynouard, P. Seyler, and R. Delmas. 2006. Methane and carbon dioxide emissions from tropical reservoirs: significance of downstream rivers. Geophysical Research Letters 33:L21407. doi:10.1029/2006GL027929.

Guérin, F., G. Abril, D. Serça, C. Delon, S. Richard, R. Delmas, A. Tremblay, and L. Varfalvy. 2007. Gas transfer velocities of $\mathrm{CO}_{2}$ and $\mathrm{CH}_{4}$ in a tropical reservoir and its river downstream. Journal of Marine Systems 66:161-172.

Hancock, P. J. 2002. Human impacts on the stream-groundwater exchange zone. Environmental Management 29:763-781.

Hansen, J., M. Sato, R. Ruedy, A. Lacis, and V. Oinas. 2000. Global warming in the twenty-first century: an alternative scenario. Proceedings of the National Academy of Sciences USA 18:9875-9880.

Harrison, J. A., P. A. Matson, and S. E. Fendorf. 2005. Effects of a diel oxygen cycle on nitrogen transformations and greenhouse gas emissions in a eutrophied subtropical stream. Aquatic Sciences 67:308-315.

Harrison, M. D., P. M. Groffman, P. M. Mayer, and S. S. Kaushal. 2012. Microbial biomass and activity in geomorphic features in forested and urban restored and degraded streams. Ecological Engineering 38:1-10.

Hedin, L. O., J. C. von Fischer, N. E. Ostrom, B. P. Kennedy, M. G. Brown, and G. P. Robertson. 1998. Thermodynamic constraints on nitrogen transformations and other biogeochemical processes at soil-stream interfaces. Ecology 79:684-703.

Heffernan, J. B., R. A. Sponseller, and S. G. Fisher. 2008. Consequences of a biogeomorphic regime shift for the hyporheic zone of a Sonoran Desert stream. Freshwater Biology 53:1954-1968.

Heilweil, V. M., P. L. Grieve, S. A. Hynek, S. L. Brantley, D. K. Solomon, and D. W. Risser. 2015. Stream measurements locate thermogenic methane fluxes in groundwater discharge in an area of shale-gas development. Environmental Science \& Technology 49:4057-4065.

Herlihy, A. T., J. L. Stoddard, and C. B. Johnson. 1998. The relationship between stream chemistry and watershed land cover data in the mid-Atlantic region, U.S. Water, Air and Soil Pollution 105:377-386.

Hertwich, E. G. 2013. Addressing biogenic greenhouse gas emissions from hydropower in LCA. Environmental Science \& Technology 47:9604-9611.

Hlaváčová, E., M. Rulík, and L. Čáp. 2005. Anaerobic microbial metabolism in hyporheic sediment of a gravel bar in a small lowland stream. River Research and Applications 21:1003-1011.

Hlaváčová, E., M. Rulík, L. Čáp, and V. Mach. 2006. Greenhouse gas $\left(\mathrm{CO}_{2}, \mathrm{CH}_{4}, \mathrm{~N}_{2} \mathrm{O}\right)$ emissions to the atmosphere from a small lowland stream in Czech Republic. Archiv für Hydrobiologie 165:339-353.

Hodgkins, S. B., M. M. Tfaily, C. K. McCalley, T. A. Logan, P. M. Crill, S. R. Saleska, V. I. Rich, and J. P. Chanton. 2014. Changes in peat chemistry associated with permafrost thaw and increased greenhouse gas production. Proceedings of the National Academy of Sciences USA 111:5, 819-5, 824.

Hooke, R. L. 2000. On the history of humans as geomorphic agents. Geology 28:843-846.

Hope, D., S. M. Palmer, M. F. Billett, and J. J. C. Dawson. 2001. Carbon dioxide and methane evasion from a temperate peatland stream. Limnology and Oceanography 46:847-857.

Hosen, J. D., O. T. McDonough, C. M. Febria, and M. A. Palmer. 2014. Dissolved organic matter quality and bioavailability changes across an urbanization gradient in headwater streams. Environmental Science \& Technology 48:7817-7824.
Hyvönen, N. P., J. T. Huttunen, N. J. Shurpali, S. E. Lind, M. E. Marushchak, L. Heitto, and P. J. Martikainen. 2013. The role of drainage ditches in greenhouse gas emissions and surface leaching losses from a cutaway peatland cultivated with a perennial bioenergy crop. Boreal Environment Research $18: 109-126$.

IPCC. 2013. Climate change 2013: the physical science basis. Contribution of Working Group I to the Fifth Assessment Report of the Intergovernmental Panel on Climate Change. Cambridge University Press, Cambridge, UK.

Jones, R. I., and J. Grey. 2011. Biogenic methane in freshwater food webs. Freshwater Biology 56:213-229.

Jones, J. B. Jr, and P. J. Mulholland. 1998a. Influence of drainage basin topography and elevation on carbon dioxide and methane supersaturation of stream water. Biogeochemistry 40:57-72.

Jones, J. B. Jr, and P. J. Mulholland. 1998b. Methane input and evasion in a hardwood forest stream: effects of subsurface flow from shallow and deep pathways. Limnology and Oceanography 43:1243-1250.

Jones, J. B. Jr, R. M. Holmes, S. G. Fisher, and N. B. Grimm. 1994. Chemoautotrophic production and respiration in the hyporheic zone of a Sonoran Desert stream. Pages 329-338 in J. A. Stanford, and H. M. Valett, editors. Proceedings of the second international conference on ground water ecology. American Water Resources Association, Herndon, Virginia, USA.

Jones, J. B. Jr, R. M. Holmes, S. G. Fisher, N. B. Grimm, and D. M. Greene. 1995. Methanogenesis in Arizona, USA dryland streams. Biogeochemistry 31:155-173.

Jones, J. B. Jr, E. H. Stanley, and P. J. Mulholland. 2003. Longterm decline in carbon dioxide supersaturation in rivers across the contiguous United States. Geophysical Research Letters 30:1495. doi:10.1029/2003GL017056.

Julian, J. P., E. H. Stanley, and M. W. Doyle. 2008. Basin-scale consequences of agricultural land use on benthic light availability and primary production along a 6th-order temperate river. Ecosystems 11:1091-1105.

Juutinen, S. M., V. Väliranta, A. M. Kuutti, T. Laine, H. Virtanen, J. Weckström. Seppä, and E.-S. Tuittila. 2013. Short-term and long-term carbon dynamics in a northern peatland-streamlake continuum: a catchment approach. Journal of Geophysical Research Biogeosciences 118:171-183.

Karl, D. M., L. Beversdorf, K. M. Björkman, M. J. Church, A. Martinez, and E. F. DeLong. 2008. Aerobic production of methane in the sea. Nature Geoscience 1:473-478.

Kaushal, S. S., G. E. Likens, N. A. Jaworski, M. L. Pace, A. M. Sides, D. Seekell, K. T. Belts, D. H. Secor, and R. L. Wingate. 2010. Rising stream and river temperatures in the United States. Frontiers in Ecology and the Environment 8:461-466.

Kaushal, S. S., P. M. Mayer, P. G. Vidon, R. M. Smith, M. J. Pennino, T. A. Newcomer, S. Duan, C. Welty, and K. T. Belt. 2014. Land use and climate variability amplify carbon, nutrient, and contaminant pulses: a review with management implications. Journal of the American Water Resources Association 50:585-614.

Keller, J. K., and S. D. Bridgham. 2007. Pathways of anaerobic carbon cycling across an ombrotrophic-minerotrophic peatland gradient. Limnology and Oceanography 52:96-107.

Keller, J. K., A. K. Bauers, S. D. Bridgham, L. E. Kellogg, and C. M. Iversen. 2006. Nutrient control of microbial carbon cycling along an ombrotrophic-minerotrophic peatland gradient. Journal of Geophysical Research: Biogeosciences 111:G03006. doi:10.1029/2005JG000152.

Keller, J. K., P. B. Weisenhorn, and P. J. Megonigal. 2009. Humic acids as electron acceptors in wetland decomposition. Soil Biology and Biochemistry 41:1518-1522. 
Kelly, C. A., et al. 1997. Increases in fluxes of greenhouse gases and methyl mercury following flooding of an experimental reservoir. Environmental Science \& Technology 31:1334-1344.

Kemenes, A., B. R. Forsberg, and J. M. Melack. 2007. Methane release below a tropical hydroelectric dam. Geophysical Research Letters 34:L12809. doi:10.1029/2007GL029479.

Kerimoglu, O., and K. Rinke. 2013. Stratification dynamics in a shallow reservoir under different hydro-meteorological scenarios and operation strategies. Water Resources Research 49:7518-7527.

Kietäväinen, R., and L. Purkamo. 2015. The origin, source, and cycling of methane in deep crystalline rock biosphere. Frontiers in Microbiology 6:725. doi:10.3389/fmicb.2015.00725.

Kirschke, S., et al. 2013. Three decades of global methane sources and sinks. Nature Geoscience 10:813-823.

Kling, G. W., G. W. Kipphut, and M. C. Miller. 1992. The flux of $\mathrm{CO}_{2}$ and $\mathrm{CH}_{4}$ from lakes and rivers in arctic Alaska. Hydrobiologia 240:23-36.

Knox, J. C. 2006. Floodplain sedimentation in the Upper Mississippi Valley: natural versus human accelerated. Geomorphology 79:286-310.

Kohzu, A., C. Kato, T. Iwata, D. Kishi, M. Murakami, S. Nakano, and E. Wada. 2004. Stream food web fueled by methane-derived carbon. Aquatic Microbial Ecology 36:189194.

Koné, Y. J. M., G. Abril, B. Delille, and A. V. Borges. 2010 Seasonal variability of methane in the rivers and lagoons of Ivory Coast (West Africa). Biogeochemistry 100:21-37.

Laiho, R. 2006. Decomposition in peatlands: reconciling seemingly contrasting results on the impacts of lowered water levels. Soil Biology and Biochemistry 38:2011-2024.

Lamontagne, R. A., J. W. Swinnerton, V. J. Linnebom, and W. D. Smith. 1973. Methane concentrations in various marine environments. Journal of Geophysical Research 78:5317-5324.

Lazar, J. G., K. Addy, M. K. Welsh, A. J. Gold, and P. M. Groffman. 2014. Resurgent beaver ponds in the Northeastern United States: implications for greenhouse gas emissions. Journal of Environmental Quality 43:1844-1852.

Lilley, M. D., M. A. de Angelis, and E. J. Olson. 1996. Methane concentrations and estimated fluxes from Pacific Northwest rivers. Mitteilungen Internationale Vereinigung für Theoretische und Angewandte Limnologie 25:187-196.

Lima, I. B. T., F. M. Ramos, L. A. W. Bambace, and R. R. Rosa. 2008. Methane emissions from large dams as renewable energy resources: a developing nation perspective. Mitigation and Adaptation Strategies to Global Change 13:193-206.

Liu, L., and T. L. Greaver. 2009. A review of nitrogen enrichment effects on three biogenic GHGs: the $\mathrm{CO}_{2}$ sink may be largely offset by stimulated $\mathrm{N}_{2} \mathrm{O}$ and $\mathrm{CH}_{4}$ emission.Ecology Letters 12:1103-1117.

Lovley, D. R., and M. J. Klug. 1986. Model for the distribution of sulfate reduction and methanogenesis in freshwater sediments. Geochimica et Cosmochimica Acta 50:11-18.

Lovley, D. R., J. D. Coates, E. L. Blunt-Harris, E. J. Phillips, and J. C. Woodward. 1996. Humic substances as electron acceptors for microbial respiration. Nature 382:445-448.

Luan, J., and J. Wu. 2015. Long-term agricultural drainage stimulates $\mathrm{CH}_{4}$ emissions from ditches through increased substrate availability in boreal peatlands. Agriculture, Ecosystems and Environment 214:68-77.

Lundin, E. J., R. Giesler, A. Persson, M. S. Thompson, and J. Karlsson. 2013. Integrating carbon emissions from lakes and streams in a subarctic catchment. Journal of Geophysical Research Biogeosciences 118:1200-1207.

Maeck, A., T. DelSontro, D. F. McGinnis, H. Fischer, S. Flury, M. Schmidt, P. Fietzek, and A. Lorke. 2013. Sediment trapping by dams creates methane emission hot spots. Environmental Science \& Technology 47:8130-8137.

Maher, D. T., I. R. Santos, J. R. F. W. Leuven, J. M. Oakes, D. V. Erler, M. C. Carvahlo, and B. D. Eyre. 2013. Novel use of cavity ring-down spectroscopy to investigate aquatic carbon cycling from microbial to ecosystem scales. Environmental Science \& Technology 47:12938-12945.

Marwick, T. R., F. Tamooh, B. Ogwoka, C. Teodoru, A. V. Borges, F. Darchambeau, and S. Bouillon. 2014. Dynamic seasonal nitrogen cycling in response to anthropogenic $\mathrm{N}$ loading in a tropical catchment, Athi-Galana-Sabaki River, Kenya. Biogeosciences 11:443-460.

Matthews, C. J., E. M. Joyce, V. L. St, S. L. Louis, J. J. Schiff, B. D. Venkiteswaran, R. A. Bodaly. Hall, and K. G. Beaty. 2005. Carbon dioxide and methane production in small reservoirs flooding upland boreal forest. Ecosystems 8:267-285

McCrackin, M. L., and J. J. Elser. 2011. Greenhouse gas dynamics in lakes receiving atmospheric nitrogen deposition. Global Biogeochemical Cycles 25:GB4005. doi:10.1029/2010GB003897.

McLinn, E. L., and T. R. Stolzenburg. 2009. Ebullitionfacilitated transport of manufactured gas plant tar from contaminated sediment. Environmental Toxicology and Chemistry 28:2298-2306.

Megonigal, J. P., M. E. Hines, and P. T. Visscher. 2004. Anaerobic metabolism: linkages to trace gases and aerobic processes. Pages 317-424 in W. H. Schlesinger, editor. Biogeochemistry. Elsevier-Pergamon, Oxford, UK.

Melton, J. R., et al. 2013. Present state of global wetland extent and wetland methane modelling: conclusions from a model inter-comparison project (WETCHIMP). Biogeosciences 10:753-788.

Minderlein, S., and C. Blodau. 2010. Humic-rich peat extracts inhibit sulfate reduction, methanogenesis, and anaerobic respiration but not acetogenesis in peat soils of a temperate bog. Soil Biology and Biochemistry 42:2078-2086.

Minkkinen, K., J. Laine, H. Nykänen, and P. J. Martikainen. 1997. Importance of drainage ditches in emissions of methane from mires drained for forestry. Canadian Journal of Forest Research 27:949-952.

Moens, N. L. W. I. 1957. Untersuchungen über den Schlamm und die Gasbildung in den Amsterdamer Grachten in den Jahre 1929 bis 1931. Hydrobiologia 9:13-24.

Montgomery, D. R. 1999. Process domains and the river continuum. Journal of the American Water Resources Association 35:397-410.

Morrice, J. A., C. N. Dahm, H. M. Valett, P. V. Unnikrishna, and M. E. Campana. 2000. Terminal electron accepting processes in the alluvial sediments of a headwater stream. Journal of the North American Benthological Society 19:593-608.

Mulholland, P. J., et al. 2008. Stream denitrification across biomes and its response to anthropogenic nitrate loading. Nature 452:202-206.

Naiman, R. J., J. M. Melillo, M. A. Lock, T. E. Ford, and S. R. Reice. 1987. Longitudinal patterns of ecosystem processes and community structure in a subarctic river continuum. Ecology 68:1139-1156.

Naiman, R. J., T. Manning, and C. A. Johnston. 1991. Beaver population fluctuations and tropospheric methane emissions in boreal wetlands. Biogeochemistry 12:1-15.

Neal, C., W. A. House, H. P. Jarvie, and A. Eatherall. 1998. The significance of dissolved carbon dioxide in major lowland rivers entering the North Sea. Science of the Total Environment 210:187-203.

Needelman, B. A., P. J. A. Kleinman, J. S. Strock, and A. L. Allen. 2007. Improved management of agricultural ditches 
for water quality protection: an overview. Journal of Soil and Water Conservation 62:171-178.

Neu, V., C. Neill, and A. V. Krusche. 2011. Gaseous and fluvial carbon export from an Amazon forest watershed. Biogeochemistry 105:133-147.

Nilsson, C., C. A. Reidy, M. Dynesius, and C. Revenga. 2005. Fragmentation and flow regulation of the World's large river systems. Science 308:405-408.

Nisbet, E. G., E. J. Dlugokencky, and P. Bousquet. 2014. Methane on the rise- again. Science 343:493-495.

Nozhevnikova, A. N., C. Holliger, A. Ammann, and A. J. B. Zehnder. 1997. Methanogenesis in sediments from deep lakes at different temperatures $\left(2-70^{\circ} \mathrm{C}\right)$. Water Science and Technology 36:57-64.

Odum, H. T. 1956. Primary production in flowing waters. Limnology and Oceanography 1:102-117.

Olson, D. M., et al. 2001. Terrestrial ecoregions of the world: a new map of life on Earth. BioScience 51:933-938.

Orr, H. G., et al. 2015. Detecting changing river temperatures in England and Wales. Hydrological Processes 29:752-766.

Ortiz-Llorente, M. J., and M. Alvarez-Cobelas. 2012. Comparison of biogenic methane emissions from unmanage estuaries, lakes, oceans, rivers and wetlands. Atmospheric Environment 59:328-337.

Palma-Silva, C., C. C. Marinho, A. F. Albertoni, I. B. Giacomini, M. P. F. Barros, L. M. Furlanetto, C. R. T. Trindade, and F. A. de Esteves. 2013. Methane emissions in two small shallow neotropical lakes: the role of temperature and trophic level. Atmospheric Environment 81:373-379.

Palviainen, M., J. Lehtoranta, P. Ekholm, T. Ruoho-Airola, and P. Kortelainen. 2015. Land cover controls the export of terminal electron acceptors from boreal catchments. Ecosystems 18:343-358. doi:10.2007/s10021-014-9832-y.

Poff, N. L., and D. D. Hart. 2002. How dams vary and why it matters for the emerging science of dam removal. BioScience 52:659-668.

Porat, I., et al. 2010. Characterization of Archaeal community in contaminated and uncontaminated surface stream sediments. Micobial Ecology 60:784-795.

Powers, S. M., J. P. Julian, M. W. Doyle, and E. H. Stanley. 2013. Retention and transport of nutrients in a mature agricultural impoundment. Journal of Geophysical Research: Biogeosciences 118:91-103.

Pulliam, W. M. 1993. Carbon dioxide and methane exports from a southeastern floodplain swamp. Ecological Monographs 63:29-53.

Purvaja, R., and R. Ramesh. 2001. Natural and anthropogenic methane emissions from coastal wetlands of South India. Environmental Management 27:547-557.

Rajkumar, A. N., J. Barnes, R. Ramesh, R. Purvaja, and R. C. Upstill-Goddard. 2008. Methane and nitrous oxide fluxes in the polluted Adyar River and estuary, SE India. Marine Pollution Bulletin 56:2043-2051.

Ramaswamy, V. 2001. Radiative forcing of climate change. Pages 349-416 in J. T. Houghton, editor. Climate change 2001: the scientific basis. Contribution of Working Group I to the Third Assessment Report of the Intergovernmental Panel on Climate Change. Cambridge University Press, Cambridge, UK.

Raymond, P. A., C. J. Zappa, D. Butman, T. L. Bott, J. Potter, P. Mulholland, A. E. Laursen, W. H. McDowell, and D. Newbold. 2012. Scaling the gas transfer velocity and hydraulic geometry in streams and small rivers. Limnology and Oceanography Fluids and Environments 2:41-53.

Raymond, P. A., et al. 2013. Global carbon dioxide emissions from inland waters. Nature 503:355-359.

Reeburgh, W. S., J. Y. King, S. K. Regli, G. W. Kling, N. A. Auerbach, and D. A. Walker. 1998. $\mathrm{A} \mathrm{CH}_{4}$ emission estimate for the Kuparek River basin, Alaska. Journal of Geophysical Research Atmospheres 103:29005-29013.

Richey, J. E., A. H. Devol, S. C. Wofsy, R. Victoria, and M. N. G. Riberio. 1988. Biogenic gases and the oxidation and reduction of carbon in Amazon River and floodplain waters. Limnology and Oceanography 33:551-561.

Roden, E. E., and R. G. Wetzel. 1996. Organic carbon oxidation and suppression of methane production by microbial $\mathrm{Fe}$ (III) oxide reduction in vegetated and unvegetated freshwater wetland sediments. Limnology and Oceanography 41:1733-1748.

Roulet, N. T., P. M. Crill, N. T. Comer, A. Dove, and R. A. Boubonniere. 1997. $\mathrm{CO}_{2}$ and $\mathrm{CH}_{4}$ flux between a boreal beaver pond and the atmosphere. Journal of Geophysical Research 102:29313-29319.

Roulet, N. T., and T. R. Moore. 1995. The effect of forestry drainage practices on the emission of methane from northern peatlands. Canadian Journal of Forest Research 25:491-499.

Rudd, J. W. M., and R. D. Hamilton. 1978. Methane cycling in a eutrophic lake and its effect on whole lake metabolism. Limnology and Oceanography 23:337-348.

Saarnio, S., W. Winiwarter, and J. Leitao. 2009. Methane release from wetlands and watercourses in Europe. Atmospheric Environment 43:1421-1429.

Sanders, I. A., C. M. Heppell, J. A. Cotton, G. Wharton, A. G. Hildrew, E. J. Flowers, and M. Trimmer. 2007. Emission of methane from chalk streams has potential implications for agricultural practices. Freshwater Biology 52:1176-1186.

Sawakuchi, H. O., D. Bastviken, A. O. Sawakuchi, A. V. Krusche, M. V. R. Ballester, and J. E. Richey. 2014. Methane emissions from Amazonian Rivers and their contribution to the global methane budget. Global Change Biology 9:2829-2840.

Scanlon, B. R., I. Jolly, M. Sophocleous, and L. Zhang. 2007. Global impacts of conversions from natural to agricultural ecosystems on water resources: quantity versus quality. Water Resources Research 43:W03437. doi:10.1029/2006WR005486.

Schindler, J. E., and D. P. Krabbenhoft. 1998. The hyporheic zone as a source of dissolved organic carbon and carbon gases to a temperate forested stream. Biogeochemistry 43 : $157-174$.

Schrier-Uijl, A. P., P. S. Kroon, P. A. Leffelaar, J. C. van Huissteden, F. Berendse, and E. M. Veenendaal. 2010. Methane emissions in two drained peat agro-ecosystems with high and low agricultural intensity. Plant and Soil 329:509-520.

Schrier-Uijl, A. P., A. J. Veraart, P. A. Leffelaar, F. Berendse, and E. M. Veenendaal. 2011. Release of $\mathrm{CO}_{2}$ and $\mathrm{CH}_{4}$ from lakes and drainage ditches in temperate wetlands. Biogeochemistry 102:265-279.

Segers, R. 1998. Methane production and methane consumption: a review of processes underlying wetland methane fluxes. Biogeochemistry 41:23-51.

Selvam, P. B., S. Natchimuthu, L. Arunachalam, and D. Bastviken. 2014. Methane and carbon dioxide emissions from inland waters in India - implications for large scale greenhouse gas balances. Global Change Biology 11:3397-3407.

Shelley, F., J. Grey, and M. Trimmer. 2014. Widespread methanotrophic primary production in lowland chalk rivers. Proceedings of the Royal Society B: Biological Sciences 281:20132854. doi:10.1098/rspb.2013.2854

Shelley, F., F. Abdullah, J. Grey, and M. Trimmer. 2015. Microbial methane cycling in the bed of a chalk river: oxidation has the potential to match methanogenesis enhanced by warming. Freshwater Biology 60:150-160.

Silvennoinen, H., A. Liikanen, J. Rintala, and P. J. Martikainen. 2008. Greenhouse gas fluxes from the eutrophic Temmesjoki River and its estuary in the Liminganlahti Bay (the Baltic Sea). Biogeochemistry 90:193-208. 
Smemo, K. A., and J. B. Yavitt. 2011. Anaerobic oxidation of methane: an underappreciated aspect of methane cycling in peatland ecosystems? Biogeosciences 8:779-793.

Smith, S. V., W. H. Renwick, J. D. Bartley, and R. W. Buddemeier. 2002. Distribution and significance of small, artificial water bodies across the United States landscape. Science of the Total Environment 299:21-36.

Solomon, C. T., E. R. Hotchkiss, J. M. Moslemi, A. J. Ulseth, E. H. Stanley, R. O. Jr Hall, and A. S. Flecker. 2009. Sediment size and nutrients regulate denitrification in a tropical stream. Journal of the North American Benthological Society 28:480-490.

Song, C., G. Yang, D. Liu, and R. Mao. 2012. Phosphorus availability as a primary constraint on methane emission from a freshwater wetland. Atmospheric Environment 59:202-206.

Song, C., L. Wang, H. Tian, D. Liu, C. Lu, X. Xu, L. Zhang, G. Yang, and Z. Wan. 2013. Effect of continued nitrogen enrichment on greenhouse gas emissions from a wetland ecosystem in the Sanjiang Plain, Northeast China: a 5 year nitrogen addition experiment. Journal of Geophysical Research Biogeosciences 118:741-751.

Sponseller, R. A., J. Temnerud, K. Bishop, and H. Laudon. 2014. Patterns and drivers of riverine nitrogen $(\mathrm{N})$ across alpine, subarctic, and boreal Sweden. Biogeochemistry 120:105-120.

Stanley, E., L. Loken, J. Crawford, N. Casson, S. Oliver, C. Gries, and S. Christel. 2015. A global database of methane concentrations and atmospheric fluxes for streams and rivers. Long Term Ecological Research Network https://portal.lternet.edu/nis/mapbrowse?packageid=knb-lter-ntl.321.5375841. doi:10.6073/pasta/21f5bd6642e9689baf90262f3c85ac4a.

Stanley, E. H., and J. T. Maxted. 2008. Changes in the dissolved nitrogen pool across land cover gradients in Wisconsin streams. Ecological Applications 18:1579-1590.

Stanley, E. H., S. M. Powers, N. R. Lottig, I. Buffam, and J. T. Crawford. 2012. Contemporary changes in dissolved organic carbon of human-dominated rivers: is there a role for DOC management? Freshwater Biology 57:26-42.

St. Louis, V. L., C. A. Kelly, E. Duchemin, J. W. Rudd, and D. M. Rosenberg. 2000. Reservoir surfaces as sources of greenhouse gases to the atmosphere: a global estimate. BioScience 50:766-775.

Striegl, R. G., M. M. Dornblaser, C. P. McDonald, J. R. Rover, and E. G. Stets. 2012. Carbon dioxide and methane emissions from the Yukon River system. Global Biogeochemical Cycles 26:GB004306. doi:10.1111/gcb.12083.

Swinnerton, J. W., V. J. Linnenbom, and C. H. Cheek. 1969. Distribution of methane and carbon monoxide between the atmosphere and natural waters. Environmental Science \& Technology 3:836-838.

Tam, T.-Y., C. I. Mayfield, and W. E. Inniss. 1981. Nitrogen fixation and methane metabolism in a stream sediment-water system amended with leaf material. Canadian Journal of Microbiology 27:511-516.

Tamene, L., S. J. Park, R. Dikau, and P. L. G. Vlek. 2006. Reservoir siltation in the semi-arid highlands of Ethiopia: sediment yield-catchment area relationship and a semi-quantitative approach for predicting sediment yield. Earth Surface Processes and Landforms 31:1364-1383.

Tang, K. W., D. F. McGinnis, K. Frindte, V. Brüchert, and H. P. Grossart. 2014. Paradox reconsidered: methane oversaturation in well-oxygenated lake waters. Limnology and Oceanography 59:275-284.

Teodoru, C. R., F. C. Nyoni, A. V. Borges, F. Darchambeau, I. Nyambe, and S. Bouillon. 2015. Dynamics of greenhouse gases $\left(\mathrm{CO}_{2}, \mathrm{CH}_{4}, \mathrm{~N}_{2} \mathrm{O}\right)$ along the Zambezi River and major tributaries, and their importance in the riverine carbon budget. Biogeosciences 12:2431-2453.
Townsend, C. R. 1989. The patch dynamics concept of stream community ecology. Journal of the North American Benthological Society 8:36-50.

Tranvik, L. J., et al. 2009. Lakes and reservoirs as regulators of carbon cycling and climate. Limnology and Oceanography 54:2298-2314.

Treat, C. C., W. M. Wollheim, R. K. Varner, A. S. Grandy, J. Talbot, and S. Frolking. 2014. Temperature and peat type control $\mathrm{CO}_{2}$ and $\mathrm{CH}_{4}$ production in Alaskan permafrost peats. Global Change Biology 20:2674-2686.

Trimmer, M., J. Grey, C. M. Heppell, A. G. Hildrew, K. Lansdow, H. Stahl, and G. Yvon-Durocher. 2012. River bed carbon and nitrogen cycling: state of play and some new directions. Science of the Total Environment 434:143-158.

Trimmer, M., A. G. Hildrew, M. C. Jackson, J. L. Pretty, and J. Grey. 2009. Evidence for the role of methane-derived carbon in a free-flowing, lowland river food web. Limnology and Oceanography 54:1541-1547.

Valett, H. M., F. R. Hauer, and J. A. Stanford. 2014. Landscape influences on ecosystem function: local and routing control of oxygen dynamics in a floodplain aquifer. Ecosystems 17:195-211.

Vannote, R. L., G. W. Minshall, K. W. Cummins, J. R. Sedell, and C. E. Cushing. 1980. The river continuum concept. Canadian Journal of Fisheries and Aquatic Sciences 37:130-137.

Venkiteswaran, J. J., S. L. Schiff, V. L. St Louis, C. J. Matthews, N. M. Boudreau, E. M. Joyce, K. G. Beaty, and R. A. Bodaly. 2013. Processes affecting greenhouse gas production in experimental boreal reservoirs. Global Biogeochemical Cycles 27:567-577.

Veraart, A. J., A. S. Steenbergh, A. Ho, S. Y. Kim, and P. L. E. Bodelier. 2015. Beyond nitrogen: the importance of phosphorus for $\mathrm{CH}_{4}$ oxidation in soils and sediments. Geoderma 259:337-346. doi:10.1016/j.geoderma.2015.03.025.

Vermaat, J. E., F. Hellmann, A. T. C. Dias, B. Hoorens, R. S. P. van Logtestijn, and R. Aerts. 2011. Greenhouse gas fluxes from Dutch peatland water bodies: importance of surrounding landscape. Wetlands 31:493-498.

Vörösmarty, C. J., et al. 2010. Global threats to human water security and river biodiversity. Nature 467:555-561.

Wallin, M. B., S. Löfgren, M. Erlandsson, and K. Bishop. 2014. Representative regional sampling of carbon dioxide and methane concentrations in hemiboreal headwater streams reveal underestimates in less systematic approaches. Global Biogeochemical Cycles 28:465-479.

Walter, K. M., L. C. Smith, and F. C. III Chapin. 2007. Methane bubbling from northern lakes: present and future contributions to the global methane budget. Philosophical Transactions: Mathematical, Physical and Engineering Sciences 365:1657-1676.

Wania, R., I. Ross, and C. Prentice. 2010. Implementation and evaluation of a new methane model within a dynamic global vegetation model: LPJ-WHyMe v1.3.1. Geoscientific Model Development 3:565-584.

Webb, B. W., D. M. Hannah, R. D. Moore, L. E. Brown, and F. Nobilis. 2008. Recent advances in stream and river temperature research. Hydrological Processes 22:902-918.

Werner, S. F., B. A. Browne, and C. T. Driscoll. 2012. Threedimensional spatial patterns of trace gas concentrations in baseflow-dominated agricultural streams: implications for surface-ground water interactions and biogeochemistry. Biogeochemistry 107:319-338.

West, W. E., J. J. Coloso, and S. E. Jones. 2012. Effects of algal and terrestrial carbon on methane production rates and methanogen community structure in a temperate lake sediment. Freshwater Biology 57:949-955. 
Whitfield, C. J., H. M. Baulch, K. P. Chun, and C. J. Westbrook. 2015. Beaver-mediated methane emission: the effects of population growth in Eurasia and the Americas. Ambio 44:7-15.

Wilcock, R. J., and B. K. Sorrell. 2008. Emissions of greenhouse gases $\mathrm{CH}_{4}$ and $\mathrm{N}_{2} \mathrm{O}$ from low-gradient streams in agriculturally developed catchments. Water Air and Soil Pollution 188: 155-170.

Wilkniss, P. E., R. A. Lamontagne, R. E. Larson, and J. W. Swinnerton. 1978. Atmospheric trace gases and land and sea breezes at the Sepik River coast of Papua New Guinea. Journal of Geophysical Research: Oceans 83:3672-3674.

Wood, P. J., and P. D. Armitage. 1997. Biological effects of fine sediment in the lotic environment. Environmental Management 21:203-217.

Wu, L. C., C. B. Wei, S. S. Yang, T. H. Chang, H. W. Pan, and Y. C. Chung. 2007. Relationship between carbon dioxide/ methane emissions and the water quality/sediment characteristics of Taiwan's main rivers. Journal of the Air and Waste Management Association 57:319-327.

Yang, L., X. Li, W. Yan, P. Ma, and J. Wange. 2012. $\mathrm{CH}_{4}$ concentrations and emissions from three rivers in the Chaohu Lake Watershed in southeast China. Journal of Integrative Agriculture 11:665-673.

Yang, S.-S., I.-C. Chen, C.-P. Liu, L.-Y. Liu, and C.-H. Chang. 2015. Carbon dioxide and methane emissions from Tanswei River in Northern Taiwan. Atmospheric Pollution Research 6:52-61

Yavitt, J. B., G. E. Lang, and A. J. Sextone. 1990. Methane fluxes in wetland and forest soils, beaver ponds, and low-order streams of a temperate forest ecosystem. Journal of Geophysical Research 95:22463-22474.

Yavitt, J. B., L. L. Angell, T. J. Fahey, C. P. Cirmo, and C. T. Driscoll. 1992. Methane fluxes, concentrations, and production in two Adirondack beaver impoundments. Limnology and Oceanography 37:1057-1066.

Yvon-Durocher, G., J. M. Montoya, G. Woodward, J. I. Jones, and M. Trimmer. 2011. Warming increases the proportion of primary production emitted as methane from freshwater mesocosms. Global Change Biology 17:1225-1234.

Yvon-Durocher, G., A. P. Allen, D. Bastviken, R. Conrad, C. Gudasz, A. St-Pierre, N. Thanh-Duc, and P. A. del Giorgio. 2014. Methane fluxes show consistent temperature dependence across microbial to ecosystem scales. Nature 507:488-491.

Zaiss, U. P., and H. Kaltwasser. 1979. Über den Enflusse wasserbaulicher Massenahmen auf die mikrobiologische Gasproduktion in Fliessegwässer-sedimenten. Archiv für Hydrobiologie 87:314-326.

Zaiss, U., P. Winter, and H. Kaltwasser. 1982. Microbial methane oxidation in the River Saar. Zeitschrift für Allgemeine Mikrobiologie 22:139-148.

Zhu, T., D. Fu, C. T. Jafvert, and R. P. Singh. 2015. Modeling gas generation from the river adjacent to the manufactured gas plant. RSC Advances 5:9565-9573.

Zhu, Q., J. Liu, C. Peng, H. Chen, X. Fang, H. Jiang, G. Yang, D. Zhu, W. Wang, and X. Zhou. 2014. Modelling methane emissions from natural wetlands by development and application of the TRIPLEX-GHG model. Geoscientific Model Development 7:981-999.

\section{SUPPORTING INFORMATION}

Additional supporting information may be found in the online version of this article at http://onlinelibrary.wiley.com/ doi/10.1890/15-1027/suppinfo

\section{Data Availability}

Data associated with this paper have been deposited in LTER: http://dx.doi.org/10.6073/pasta/21f5bd6642e9689baf90262f3c85ac4a 